\title{
Synthesis and Preclinical Evaluation of the First Carbon-11 Labeled PET Tracers Targeting Substance $P_{1-7}$
}

Aleksandra Pekošak, ${ }^{\circledR}$ Janez Ž. Bulc, ${ }^{\S}$ Špela Korat, ${ }^{\S}$ Robert C. Schuit, Esther Kooijman, Ricardo Vos, Marissa Rongen, Mariska Verlaan, Kevin Takkenkamp, Wissam Beaino, Alex J. Poot, and Albert D. Windhorst*

Department of Radiology and Nuclear Medicine, VU University Medical Center, 1081 HV Amsterdam, The Netherlands

\section{Supporting Information}

ABSTRACT: Two potent $\mathrm{SP}_{1-7}$ peptidomimetics have been successfully radiolabeled via $\left[{ }^{11} \mathrm{C}\right] \mathrm{CO}_{2}$-fixation with excellent yields, purity, and molar activity. $\mathrm{L}^{-}\left[{ }^{11} \mathrm{C}\right] \mathrm{SP}_{1-7}$-peptidomimetic exhibited promising ex vivo biodistribution profile. Metabolite analysis showed that $\mathrm{L}-\left[{ }^{11} \mathrm{C}\right] \mathrm{SP}_{1-7}$-peptidomimetic is stable in brain and spinal cord, whereas rapid metabolic degradation occurs in rat plasma. Metabolic stability can be significantly improved by substituting L-Phe for D-Phe,

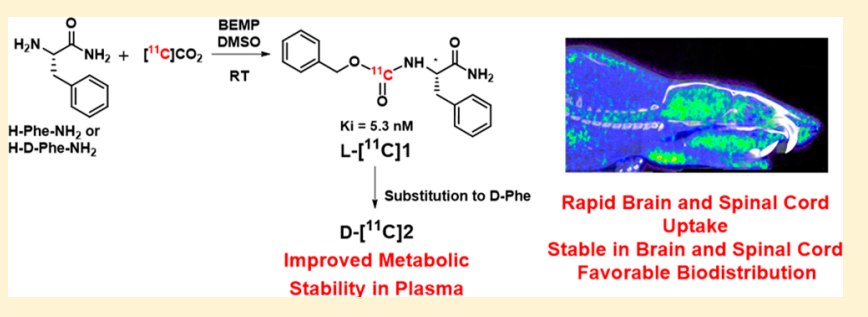
preserving $70 \%$ more of intact tracer and resulting in better brain and spinal cord tracer retention. Positron emission tomography (PET) scanning confirmed moderate brain (1.5 SUV; peak at $3 \mathrm{~min})$ and spinal cord $(1.0 \mathrm{SUV}$; peak at $10 \mathrm{~min})$ uptake for $\mathrm{L}-$ and $\mathrm{D}-\left[{ }^{11} \mathrm{C}\right] \mathrm{SP}_{1-7}$-peptidomimetic. A slight decrease in SUV value was observed after pretreatment with natural peptide $\mathrm{SP}_{1-7}$ in spinal cord for $\mathrm{L}-\left[{ }^{11} \mathrm{C}\right] \mathrm{SP}_{1-7}$-peptidomimetic. On the contrary, blocking using cold analogues of $\mathrm{L}^{-}$and $\mathrm{D}-\left[{ }^{11} \mathrm{C}\right]$ tracers did not reduce the tracers' brain and spinal cord exposure. In summary, PET scanning of $\mathrm{L}_{-}$and $\mathrm{D}-\left[{ }^{11} \mathrm{C}\right] \mathrm{SP}_{1-7}$-peptidomimetics confirms rapid blood-brain barrier and blood-spinal-cord barrier penetration. Therefore, further validation of these two tracers targeting $\mathrm{SP}_{1-7}$ is needed in order to define a new $\mathrm{PET}$ imaging target and select its most appropriate radiopharmaceutical.

KEYWORDS: substance $P_{1-7}, \mathrm{CO}_{2}$ fixation, carbon-11, metabolism, biodistribution, PET imaging

\section{INTRODUCTION}

Substance P (SP) (H-Arg-Pro-Lys-Pro-Gln-Gln-Phe-Phe-GlyLeu-Met- $\mathrm{NH}_{2}$ ) is a neurotransmitter and neuromodulator involved in a variety of neurological functions. Its role in pain transmission has attracted particular interest, since SP binds preferably to the neurokinin 1 receptor (NK-1R); however, the $\mathrm{SP} N$-terminal major bioactive fragment $\mathrm{SP}_{1-7}$ (H-Arg-ProLys-Pro-Gln-Gln-Phe-OH) acts through binding to a specific site apart from any known neurokinin or opioid receptor. The absence of binding of $\mathrm{SP}_{1-7}$ to the NK-1R is attributed to the lack of the amidated amino acid sequence Gly ${ }^{9}-$ Leu $^{10}-$ Met $^{11}$ $\mathrm{NH}_{2}$ on the $C$-terminus. ${ }^{1-7}$

$\mathrm{SP}_{1-7}$ has been shown to be present in various central nervous system (CNS) areas, such as hypothalamus, nucleus accumbens, ventral tragemental area, and in the dorsal and ventral part of spinal cord, confirming that the heptapeptide is related to pain and reward processing when produced in the CNS by endopeptidases. ${ }^{8-10}$ Even though the binding sites in mouse and rat are known, the receptor for $\mathrm{SP}_{1-7}$ has not yet been cloned or characterized, making its mechanism of action remain unclear. ${ }^{8,11}$ Recently, in vitro and in vivo studies showed improved binding affinity of amidated $C$-terminus $\mathrm{SP}_{1-7}-\mathrm{NH}_{2}$ compared to the endogenous fragment $\mathrm{SP}_{1-7}$, as well as increased potency effect to mediate a reduced expression of opioid withdrawal through the $\mathrm{SP}_{1-7}$ binding site. ${ }^{12,13}$ In addition, the $\mathrm{SP}_{1-7}$ analog D-SP ${ }_{1-7}\left(\mathrm{D}-\mathrm{Pro}^{2}-\mathrm{D}-\mathrm{Phe}^{7}-\mathrm{SP}_{1-7}\right)$ was able to block $\mathrm{SP}_{1-7}$ induced antinociception and showed binding affinity to $\mathrm{SP}_{1-7}$ binding site equipotent to natural $\mathrm{SP}_{1-7} \cdot 1,14,15$ Interestingly, the $\mathrm{SP}_{1-7}-\mathrm{NH}_{2}$ showed higher antiallodynic activity after intraperitoneal administration compared to $\mathrm{SP}_{1-7}$ despite the poor in vivo stability of both peptides.

Aiming to develop a peptidomimetic with a long duration of action and ability to cross the blood-brain barrier (BBB), Fransson et al.performed extensive structure-activity relationship (SAR) studies resulting in a lead dipeptide H-Phe-Phe$\mathrm{NH}_{2}$ ( $K_{\mathrm{i}}$ of $1.5 \mathrm{nM}$; rat spinal cord membrane) as small molecule to target the $\mathrm{SP}_{1-7}$ binding site. ${ }^{5,12}$ Further finetuning, by replacing the $N$-terminal Phe with a benzylcarbamate group, resulted in a peptidomimetic $(S)$-benzyl (1-amino1-oxo-3-phenylpropan-2-yl)carbamate $\mathrm{L}-1$ with a $K_{\mathrm{i}}$ of $5.2 \mathrm{nM}$, determined by using rat spinal cord membranes preparation (Figure 1). ${ }^{1,11,16}$ Its reasonable binding affinity, excellent membrane permeability, low efflux, moderate in vitro clearance, and ability to enter the CNS according to the in vivo infusion

Received: May 16, 2018

Revised: August 20, 2018

Accepted: October 18, 2018

Published: October 18, 2018 

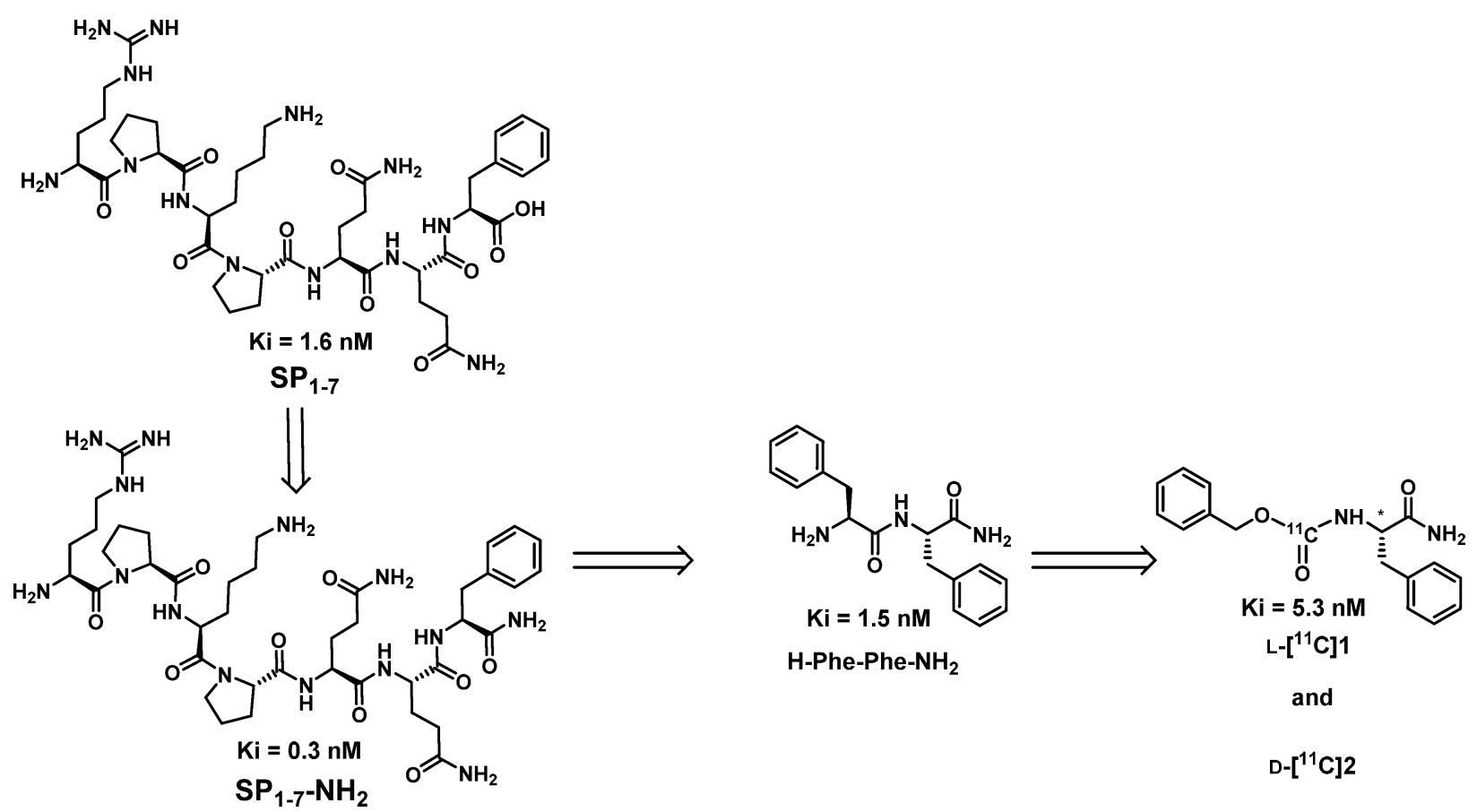

Figure 1. Structure of $\mathrm{SP}_{1-7}$ and $\mathrm{SP}_{1-7}-\mathrm{NH}_{2}$ as leads for the development of small molecules, $\mathrm{H}-\mathrm{Phe}-\mathrm{Phe}-\mathrm{NH}_{2}$, and the peptidomimetics L-1 and $\mathrm{D}$ 2. Red ${ }^{11} \mathrm{C}$ indicates the radiolabeling position using the $\left[{ }^{11} \mathrm{C}\right] \mathrm{CO}_{2}$-fixation method.

study make $\mathrm{SP}_{1-7}$ an interesting target for PET tracer development.

Neuropathic pain is clinically characterized by spontaneous and evoked type of pain significantly impairing the quality of patients' life, whereas an effective treatment represents a major unsolved problem. ${ }^{17}$ Developing PET-tracers able to image and evaluate neuropathic pain would provide a valuable tool for better estimation of the incidence and prevalence of neuropathic pain, and treatment development. ${ }^{18} \mathrm{SP}_{1-7}$ is a relatively large molecule and current radiolabeling techniques require a strong modification of the native peptide structure hampering the $\mathrm{BBB}$ penetration. Nonetheless, the dipeptide peptidomimetics are more attractive alternatives and could be viable neuro PET tracers able to cross the BBB. Positron emission tomography (PET) imaging is a powerful technique that provides direct quantitative information on the levels of brain and spinal cord exposure, target engagement, and pharmacological activity. ${ }^{19,20}$ In our study, we used dipeptide peptidomimetics (Figure 1) for radiolabeling with carbon-11 in order to investigate the $\mathrm{SP}_{1-7}$ binding site and provide insights in the potential neuropathic pain PET imaging.

The merits of carbon-11 $\left(t_{1 / 2}=20.4 \mathrm{~min}, 99 \% \beta+, 0.96\right.$ $\mathrm{MeV}$ ) as a choice radionuclide for PET tracer synthesis have been well recognized. The ubiquity of carbon atoms in all pharmacologically active compounds makes it an attractive isotope for radiolabeling, preserving the favorable physicochemical properties. ${ }^{21-28}$ With the recent developments in carbon-11 chemistry, routinely employed complex processes, and appropriate special equipment, radiochemists are able to label various compounds. Direct fixation of $\left.{ }^{11} \mathrm{C}\right] \mathrm{CO}_{2}$, published by Hooker et al. ${ }^{29}$ and Wilson et al., ${ }^{30}$ addressing the carbon-11 labeled carbamate functional group, enables us to label the $\mathrm{SP}_{1-7}$ peptidomimetic $(S)$-benzyl (1-amino-1-oxo3-phenylpropan-2-yl)carbamate L-1 or (R)-benzyl (1-amino-1oxo-3-phenylpropan-2-yl)carbamate $\mathbf{D}-2$ (Figure 1) to serve as a research tool to investigate the $\mathrm{SP}_{1-7}$ binding site. To achieve this goal, we first investigated their physiochemical properties using the novel tool CNS PET multiparameter optimization (MPO) algorithm, ${ }^{31,32}$ as well as a commercial platform for in silico prediction of physicochemical, absorption, distribution, metabolism, and excretion (ADME), and toxicity properties, to provide valuable information if compounds of interest meet a distinctive set of criteria for CNS PET ligand. As prediction models provided an enviable starting point for PET ligand discovery effort, we investigated the feasibility of carbon-11 radiolabeling of compounds $\mathbf{1}$ and $\mathbf{2}$ without further modifications. Finally, we evaluated their biodistribution and in vivo metabolic stability and assessed their in vivo behavior in brain and spinal cord using PET imaging.

\section{EXPERIMENTAL SECTION}

Materials and Methods. Chemicals were obtained commercially from Sigma-Aldrich (Zwijndrecht, The Netherlands) and Bachem (Bubendorf, Switzerland), and used without further purification, unless stated otherwise. Solvents were purchased from Biosolve (Valkenswaard, The Netherlands) and Acros (Landsmeer, The Netherlands), and used as received, unless stated otherwise. All deuterated solvents were purchased from Sigma-Aldrich (Zwijndrecht, The Netherlands). Reactions were performed at ambient temperature unless stated otherwise and monitored by thin layer chromatography on precoated silica $60 \mathrm{~F}_{254}$ aluminum plates (Merck, Darmstadt, Germany). Spots were visualized by UV light $(254 \mathrm{~nm})$ and ninhydrine or bromocresol green staining. Solvents were evaporated under reduced pressure using a rotary evaporator (Rotavapor R II, Flawil, Switzerland). Flash column chromatography was performed on Büchi (Flawil, Switzerland) Sepacore system (comprising a C-620 control unit, a C-660 fraction collector, two C-601 gradient pumps and a C-640 UV detector) equipped with Büchi Sepacore prepacked flash columns. Yields refer to purified and spectroscopically pure compounds. 
NMR spectroscopy was performed on a Bruker Avance 250, 400 , or $500 \mathrm{MHz}$ spectrometer (Billerica, MA, USA, exact magnetic field is reported in the Chemical Syntheses section) with chemical shifts $(\delta)$ reported in parts per million (ppm) relative to the solvent $\left(\mathrm{CDCl}_{3},{ }^{1} \mathrm{H} 7.26 \mathrm{ppm},{ }^{13} \mathrm{C} 77.16 \mathrm{ppm}\right.$; $\mathrm{D}_{2} \mathrm{O},{ }^{1} \mathrm{H} 4.79$ ppm; $\left.\left(\mathrm{CD}_{3}\right)_{2} \mathrm{SO},{ }^{13} \mathrm{C} 39.52 \mathrm{ppm}\right)$. Splitting patterns are indicated as s, singlet; $d$, doublet; $\mathrm{t}$, triplet; $q$, quartet; m, multiplet; br, broad peak, dd, double doublet, and J, coupling constant in Hz. Electrospray ionization-high resolution mass spectrometry (ESI-HRMS) was carried out using Bruker microTOF-Q instrument in a positive ion mode (capillary potential of $4500 \mathrm{~V}$ ) and interpreted with Bruker Compass Data Analysis 4.0 software.

Analytical HPLC was performed on a Shimadzu SPD-20A system (Shimadzu Corporation, Japan) and Jasco PU-2089 Plus station (Easton, MD, USA) with a Alltima C18 $5 \mu \mathrm{m}(250$ $\times 4.6 \mathrm{~mm}$ ) column (Grace, Breda, The Netherlands) (A) with Jasco UV-2075 Plus UV detector $(254 \mathrm{~nm})$ and NaI radioactivity detector (Raytest, Straubenhardt, Germany) at ambient temperature with a flow rate $1 \mathrm{~mL} \cdot \mathrm{min}^{-1}$. Acetonitrile (C), acetonitrile $+0.1 \%$ TFA (D), water (E), water $+0.1 \%$ TFA (F), and buffer 1 (4 mM sodium formate and $4 \%$ dimethylformamide) (G) were used as mobile phases. Chromatograms were acquired with LabSolutions 5.85 software (Shimadzu Corporation, Japan) and Raytest GINA Star software (version 5.8; Straubenhardt, Germany).

* Method A: solvents D/F $(v / v)$, linear gradient, 0-1 min, $35 \% \mathrm{D} ; 1-19 \mathrm{~min}, 35-65 \% \mathrm{D}$; $19-20 \mathrm{~min}, 65-35 \% \mathrm{D} ; 20-$ $21 \mathrm{~min}, 65 \% \mathrm{D}$.

Semipreparative isocratic HPLC was performed on Jasco UV-2087 Plus station with a Alltima C18 $5 \mu \mathrm{m}(250 \times 10$ $\mathrm{mm}$ ) column (Grace, Breda, The Netherlands) (J) using C/G $(40 / 60, v / v)$ as a eluent, flow rate $5 \mathrm{~mL} \cdot \mathrm{min}^{-1}$ (Method B), a Jasco UV-2075 Plus UV detector (254 nm), a homemade radioactivity detector, and Jasco ChromNAV CFR software (version 1.14.01).

HPLC conditions for metabolite analysis and LC-MS/MS analysis are, for convenience, reported under each appropriate section.

\section{Prediction Models.}

- ACD Laboratories, Percepta:

Full array of physiochemical, $\mathrm{ADME}$, and toxicity properties, next to $\mathrm{BBB}$ transport parameters, were predicted using the commercial package of ACD/ Percepta (version: 14.2.0 (Build 2972)).

- CNS PET Multi Parameter Optimization (MPO):

CNS PET MPO value was calculated using a set of six physiochemical parameters:

- molecular weight (Mw)

- lipophilicity, calculated partition coefficient (ClogP)

- calculated distribution coefficient at $\mathrm{pH}=7.4(\mathrm{ClogD})$

- topological polar surface area (tPSA)

- ionization constant of the most basic center $\left(\mathrm{p} K_{\mathrm{a}}\right)$

- number of hydrogen bond donors (HBD)

following the publication of Zhang et al. ${ }^{31}$ and standard commercial packages described in the paper of Wager et al. ${ }^{33}$

List of standard commercial packages: Biobyte (Bio-Loom; version 5) for $\mathrm{Clog}$; $\mathrm{ACD} /$ Percepta for $\mathrm{ClogD}$ at $\mathrm{pH}=7.4$, tPSA, $\mathrm{p} K_{\mathrm{a}}$; ChemDraw (professional; version: 16.0.1.4 (77)) for Mw and HBD.

Calculation of the Radiochemical Yield by Analytical HPLC. Radiochemical yield, determined by analytical HPLC of the crude reaction mixture, defined as radiochemical conversion (RCC), was determined by HPLC as the percentage of converted $\left[{ }^{11} \mathrm{C}\right] \mathrm{CO}_{2}$ to desired product $\left[{ }^{11} \mathrm{C}\right] \mathbf{1}$ or $\left[{ }^{11} \mathrm{C}\right] 2$ in the crude reaction mixture using an analytical HPLC method described in the Radiochemistry section under each procedure and is based on the area under the curve (AUC) of the radioactivity profile of HPLC analysis.

Calculation of the Radiochemical Yield. Radiochemical yield (RCY) was calculated as the quotient of measured activity of the isolated product at the end of the synthesis (EOS) and the measured activity at the end of the cyclotron bombardment (EOB) and expressed as a percentage. Radiochemical yield has been corrected for decay from the EOB. No corrections have been made for material losses (potentially volatile radioactive species or residual activity in the vial, tubes, and syringes).

Calculation of the Molar Activity. Molar activity $\left(A_{\mathrm{M}}\right)$ of the final tracer, expressed as $\mathrm{GBq} \cdot \mu \mathrm{mol}^{-1}$, was determined by measurement of the UV absorbance (AUC) of a known amount of radioactivity under identical analytical HPLC conditions used to generate a mass calibration curve for the corresponding nonradioactive standard.

The Mass Calibration Curve. The mass calibration curve was performed using samples of the reference compound 1 due to strong UV absorption and is based on the AUC of HPLC analysis.

Chemical Syntheses. (S)-Benzyl (1-Amino-1-oxo-3-phenylpropan-2-yl)carbamate (1). Starting compound (S)-2(((benzyloxy)carbonyl)amino)-3-phenylpropanoic acid (80.0 $\mathrm{mg}, 267 \mu \mathrm{mol}, 1$ equiv) and di-tert-butyl dicarbonate $(125 \mathrm{mg}$, $573 \mu \mathrm{mol}, 2$ equiv) were dissolved in $3 \mathrm{~mL}$ of 1,4-dioxane and placed on a magnetic mixer. Pyridine $(18.0 \mu \mathrm{L}, 267 \mu \mathrm{mol}, 1$ equiv) and ammonium hydrogen carbonate $(58.0 \mathrm{mg}, 746$ $\mu$ mol, 2.8 equiv) were added to the solution. The reaction mixture was flushed with nitrogen and left stirring overnight $(17 \mathrm{~h})$. Solvents were evaporated in vacuo. The remaining material in the vessel was dissolved in $7 \mathrm{~mL}$ of ethyl acetate (EtOAc) and washed three times with $5 \mathrm{~mL}$ of $5 \mathrm{mM} \mathrm{H}_{2} \mathrm{SO}_{4}$ and three times with $5 \mathrm{~mL}$ of brine. The organic phases were combined, dried over $\mathrm{MgSO}_{4}$, filtered, and evaporated in vacuo. Compound 1 was obtained in $80 \%$ yield as a white crystalline powder after precipitation in ice-cold $n$-hexane. ${ }^{1} \mathrm{H}$ NMR $\left(250.13 \mathrm{MHz}, \mathrm{DMSO}-d_{6}\right): \delta(\mathrm{ppm})=7.50(\mathrm{br} \mathrm{s}, 1 \mathrm{H},-\mathrm{NH}-)$, $7.31-7.19$ (m, 10H, 10x Ar- $\underline{\mathrm{H}}), 7.07$ (s, 2H, $-\mathrm{N}_{2}$ ), 4.91 (s, $\left.2 \mathrm{H},-\mathrm{CH}_{2}-\mathrm{O}\right), 4.19-4.10\left(\mathrm{~m}, 1 \mathrm{H},-\mathrm{CH}-\mathrm{CH}_{2}-\right), 3.00$ (dd, $\left.J_{1}=22 \mathrm{~Hz}, J_{2}=8 \mathrm{~Hz}, 1 \mathrm{H}, \mathrm{CH}_{2}-\mathrm{CH}-\right), 2.75-2.66(\mathrm{~m}, 1 \mathrm{H}$, $\left.\mathrm{C}_{2}-\mathrm{CH}-\right) .{ }^{13} \mathrm{C}$ NMR $\left(125.81 \mathrm{MHz}, \mathrm{DMSO}-d_{6}\right): \delta(\mathrm{ppm})=$ $174.05\left(-\mathrm{CONH}_{2}\right), 160.09$ (- $\left.\underline{\mathrm{COONH}}-\right), 138.61$ (Ar), 129.61 (Ar), 128.76 (Ar), $128.53(\mathrm{Ar}), 127.85$ (Ar), 126.74 (Ar), $74.94\left(-\mathrm{CH}_{2} \mathrm{O}-\right)$, 65.64 (- $\left.-\underline{\mathrm{H}}-\right)$, $37.91\left(-\mathrm{CH}_{2} \mathrm{CH}-\right)$. HRMS: Calculated for $\mathrm{C}_{17} \mathrm{H}_{18} \mathrm{~N}_{2} \mathrm{O}_{3}$ 298.1317, measured 299.1225 $\left(\mathrm{M}+\mathrm{H}^{+}\right)$and $321.1225\left(\mathrm{M}+\mathrm{Na}^{+}\right)$. HPLC purity: $>99 \%$ (determined by HPLC: column A, method A, $R_{\mathrm{t}}=11.8$ $\min )$.

Synthesis of (R)-Benzyl (1-Amino-1-oxo-3-phenylpropan2-yl)carbamate (2). Starting compound (R)-2-(((benzyloxy)carbonyl)amino)-3-phenylpropanoic acid (100 mg, $334 \mu \mathrm{mol}$, 1 equiv) and di-tert-butyl dicarbonate $(183 \mathrm{mg}, 668 \mu \mathrm{mol}, 2$ equiv) were dissolved in $3 \mathrm{~mL}$ of 1,4-dioxane and placed on a magnetic mixer. Pyridine $(27.0 \mu \mathrm{L}, 334 \mu \mathrm{mol}, 1$ equiv) and ammonium hydrogen carbonate $(75.0 \mathrm{mg}, 868 \mu \mathrm{mol}, 2.6$ equiv) were added to the solution. Nitrogen atmosphere was introduced before the solution was left stirring overnight (18 
h). Solvents were evaporated in vacuo. The remaining material in the vessel was dissolved in $7 \mathrm{~mL}$ of EtOAc, washed three times with $5 \mathrm{~mL}$ of $5 \mathrm{mM} \mathrm{H}_{2} \mathrm{SO}_{4}$, and three times with $5 \mathrm{~mL}$ of brine. The organic phases were combined, dried over $\mathrm{MgSO}_{4}$, filtered, and evaporated in vacuo. Compound 2 was obtained in $55 \%$ yield as a white crystalline powder after precipitation in ice-cold $n$-hexane. ${ }^{1} \mathrm{H}$ NMR $(400.13 \mathrm{MHz}$, DMSO- $\left.d_{6}\right): \delta(\mathrm{ppm})=7.47($ br s, $1 \mathrm{H},-\mathrm{N} \underline{\mathrm{H}}-), 7.41-7.21$ $(\mathrm{m}, 10 \mathrm{H}, 10 \mathrm{x} \mathrm{Ar}-\mathrm{H}), 7.07\left(\mathrm{~s}, 2 \mathrm{H},-\mathrm{N}_{2}\right), 4.94(\mathrm{~s}, 2 \mathrm{H}$, $-\underline{\mathrm{C}}_{2}-\mathrm{O}$ ), $4.19-4.16\left(\mathrm{~m}, 1 \mathrm{H},-\mathrm{CH}-\mathrm{CH}_{2}-\right.$ ), 3.00 (dd, $J_{1}=$ $\left.16 \mathrm{~Hz}, J_{2}=4 \mathrm{~Hz}, 1 \mathrm{H}, \mathrm{CH}_{2}-\mathrm{CH}-\right), 2.74(\mathrm{t}, J=12 \mathrm{~Hz}, 1 \mathrm{H}$, $\left.\mathrm{CH}_{2}-\mathrm{CH}-\right) .{ }^{13} \mathrm{C}$ NMR $\left(125.81 \mathrm{MHz}\right.$, DMSO-d $\left.d_{6}\right): \delta(\mathrm{ppm})=$ $173.88\left(-\mathrm{CONH}_{2}\right), 153.30(-\underline{\mathrm{COONH}}-), 138.77(\mathrm{Ar})$, 137.52 (Ar), 128.93 (Ar), 128.73 (Ar), 128.49 (Ar), 127.88 (Ar), $126.66(\mathrm{Ar}), 65.58\left(-\mathrm{CH}_{2} \mathrm{O}-\right), 65.54(-\underline{\mathrm{CH}}-), 37.96$ (- $\mathrm{CH}_{2} \mathrm{CH}-$ ). HRMS: Calculated for $\mathrm{C}_{17} \mathrm{H}_{18} \mathrm{~N}_{2} \mathrm{O}_{3}$ 298.1317, measured 299.1378 $(\mathrm{M}+\mathrm{H})^{+}$and $321.1199(\mathrm{M}+\mathrm{Na})^{+}$. HPLC purity: $>95 \%$ (determined by HPLC: column A, method A, $\left.R_{\mathrm{t}}=11.8 \mathrm{~min}\right)$.

Radiosynthesis. Radionuclide Production Procedure for Carbon-11. An IBA Cyclone 18/9 (IBA, Louvain-la Neuve, Belgium) cyclotron was used for $\left[{ }^{11} \mathrm{C}\right] \mathrm{CO}_{2}$ production by the ${ }^{14} \mathrm{~N}(\mathrm{p}, \alpha){ }^{11} \mathrm{C}$ nuclear reaction performed in a $0.5 \% \mathrm{O}_{2} / \mathrm{N}_{2}$ gas mixture. After trapping of $\left[{ }^{11} \mathrm{C}\right] \mathrm{CO}_{2}$ from the target in a stainless trap dispersed in liquid $\mathrm{N}_{2},\left[{ }^{11} \mathrm{C}\right] \mathrm{CO}_{2}$ was transferred to the desired reaction vessel using a $10 \mathrm{~mL} \cdot \mathrm{min}^{-1}$ helium flow.

Procedure of the Manual Synthesis of (S)- $\left[{ }^{11} \mathrm{C}\right]$ Benzyl (1Amino-1-oxo-3-phenylpropan-2-yl)carbamate. H-L-Phe$\mathrm{NH}_{2}$ was placed in a predried reaction vessel in a research hot-cell and dissolved in DMSO containing BEMP. $\left[{ }^{11} \mathrm{C}\right] \mathrm{CO}_{2}$ (4-6 GBq) was transferred through a sicapent (phosphorus pentoxide) column to the mixture using helium flow of $10 \mathrm{~mL}$. $\mathrm{min}^{-1}$ from a $\mathrm{CO}_{2}$ trap. When the activity in the vessel reached its maximum, DMSO containing benzyl chloride was manually added to the reaction vessel with a syringe, heated to $75{ }^{\circ} \mathrm{C}$ and left to stir with helium flow $\left(10 \mathrm{~mL} \cdot \mathrm{min}^{-1}\right)$ for 2-10 $\mathrm{min}$. Approximately $50 \mu \mathrm{L}$ of the reaction mixture was then quenched with $300 \mu \mathrm{L}$ of solution of acetonitrile and water $(1 / 1 ; v / v)$ and analyzed on HPLC (Column A; Method A) to determine the radiochemical yield expressed as radiochemical conversion of the reaction.

Procedure for the Automated Synthesis of (S)- $\left[{ }^{11} \mathrm{C}\right]$ Benzyl (1-Amino-1-oxo-3-phenylpropan-2-yl)carbamate $\left(\left[{ }^{11} \mathrm{C}\right] 1\right)$ and of $(R)-\left[{ }^{11} C\right]$ Benzyl (1-Amino-1-oxo-3-phenylpropan-2yl)carbamate $\left(\left[{ }^{11} \mathrm{C}\right] 2\right)$. H-L-Phe- $\mathrm{NH}_{2}$ or H-D-Phe- $\mathrm{NH}_{2}$ (1.0 $\mathrm{mg}, 3.3 \mu \mathrm{mol})$ was placed in a predried reaction vessel dissolved in DMSO $(0.15 \mathrm{~mL})$ containing BEMP $(8.3 \mu \mathrm{L})$ and fixed in the home-build synthesis module located in the hotcell. ${ }^{34}\left[{ }^{11} \mathrm{C}\right] \mathrm{CO}_{2}(45 \mathrm{GBq})$ was transferred through a sicapent column to the mixture using helium flow $\left(10 \mathrm{~mL} \cdot \mathrm{min}^{-1}\right)$. When the activity in the vessel reached its maximum, benzyl chloride $(4.0 \mu \mathrm{L})$ in DMSO $(0.15 \mathrm{~mL})$ was automatically added to the reaction vessel, which was then heated to $75{ }^{\circ} \mathrm{C}$ and left to stir with helium $\left(10 \mathrm{~mL} \cdot \mathrm{min}^{-1}\right)$ for $5 \mathrm{~min}$. The mixture was then cooled to $25^{\circ} \mathrm{C}$, quenched with a solution of acetonitrile and water $(1 / 1 ; v / v ; 1.5 \mathrm{~mL})$ and injected on a preparative HPLC column (Column J, Method B). The product, eluting between 12 and $14 \mathrm{~min}$, was collected (Supporting Information Figure 2), diluted in $7 \mathrm{~mL}$ of water and loaded on a preconditioned Sep-Pak $\mathrm{C}_{18}$ column. The SepPak $\mathrm{C}_{18}$ column was washed with $5 \mathrm{~mL}$ of water, before the product was eluted with $1 \mathrm{~mL}$ of ethanol (EtOH). Saline solution $(9 \mathrm{~mL})$ was added to the product, forming the final injectable radioactive tracer.

$\left[{ }^{11} \mathrm{C}\right] \mathbf{1}$ was obtained in a decay-corrected radiochemical yield of $27.9 \pm 10.9 \%(n=10)$ with an isolated nondecaycorrected yield of $5.1 \pm 2.2 \mathrm{GBq}(n=10)$ of the product with a radiochemical purity $>99 \%$, an average $A_{\mathrm{M}}$ of $93.2 \pm 46.9$ $\mathrm{GBq} \cdot \mu \mathrm{mol}^{-1}(n=9)$ within $24-26 \mathrm{~min}(n>10)$. The identity of the product was confirmed with analytical HPLC (Column A; Method A) by coinjection of the product and nonlabeled 1 (Supporting Information Figure 3).

$\left[{ }^{11} \mathrm{C}\right] 2$ was obtained in a decay-corrected radiochemical yield of $25.5 \pm 9.7 \%(n=5)$ with an isolated noncorrected yield of $3.9 \pm 1.9 \mathrm{GBq}(n=5)$ of the product with a radiochemical purity $>99 \%$, an average $A_{\mathrm{M}}$ of $69.4 \pm 11.4$ $\mathrm{GBq} \cdot \mu \mathrm{mol}^{-1}(n=4)$ within $23-29 \mathrm{~min}(n=5)$. The identity of the product was confirmed with analytical HPLC (Column A; Method A) by coinjection of the product and nonradiolabeled 2.

Animals. Adult healthy male Wistar rats $(200-360$ g; 7-10 weeks; Charles River International Inc., Sulzfeld, Germany) were housed in groups of six maximum in a conventional cage and kept in ambient conditions with a $12 \mathrm{~h}$ light/dark cycle, constant temperature $\left(19-21^{\circ} \mathrm{C}\right.$ ), and humidity level (52$70 \%$ ). Rats were provided with water and food pellets (Teklad Global Diet 2016, Envigo; Horst, The Netherlands) ad libitum. The rats were allowed to adapt to the laboratory environment for 1 week before the experiment. Animal experiments were performed in accordance with the European Community Council Directive (2010/63/EU) for laboratory animal care and the Dutch Law on animal experimentation. The experimental protocol was validated and approved by the local committee on animal experimentation of the $\mathrm{VU}$ University Medical Center.

Ex vivo Biodistribution. Healthy male Wistar rats (200$250 \mathrm{~g})$ were injected with the radiotracer $(25.8 \pm 7.6 \mathrm{MBq}$; $0.74 \pm 0.21 \mathrm{nmol} ; n=16)$ via the tail vein under isoflurane anesthesia $\left(2-2.5 \%\right.$ in $\left.1 \mathrm{~L} \cdot \mathrm{min}^{-1}\right)$. Animals were sacrificed and dissected at $5,15,30$, and $60 \mathrm{~min}(n=4$ per time point $)$ postinjection. Blood, heart, lungs, liver, kidney, duodenum, urine, tail, bone, spleen, large brain, cerebellum, brain stem, spinal cord top, and spinal cord mid were collected, weighed, and counted for radioactivity in a Wallac Computagama 1210 or a Wallac Universal Gamma Counter 1282 (Wallac, PerkinElmer, Waltham, MA, USA). Biodistribution data are expressed as the percentage of injected dose per gram (\%ID/ g). Errors are standard error of the mean (SEM).

Metabolites Analysis (Plasma and Brain). Healthy male Wistar rats $(200-330 \mathrm{~g})$ were injected with the tracer $\left[{ }^{11} \mathrm{C}\right] \mathbf{1}$ $(27.3 \pm 7.3 \mathrm{MBq} ; 0.50 \pm 0.22 \mathrm{nmol} ; n=12)$ or $\left[{ }^{11} \mathrm{C}\right] 2(32.4$ $\pm 3.4 \mathrm{MBq} ; 1.80 \pm 0.19 \mathrm{nmol} ; n=9)$ via the tail vein under isoflurane anesthesia $\left(2-2.5 \%\right.$ in $\left.1 \mathrm{~L} \cdot \mathrm{min}^{-1}\right)$. The rodents were sacrificed at 5,15 , and $45 \mathrm{~min}$ postinjection for the tracer $\left[{ }^{11} \mathrm{C}\right]$ 1 ( $n=4$ per time point) and at 5,15 , and 45 min postinjection for the tracer $\left[{ }^{11} \mathrm{C}\right] 2$ ( $n=3$ per time point). Blood (2.0-5.0 $\mathrm{mL}$ ) was collected via heart puncture into heparin tubes (DB Vacutainer, LH, Becton Dickinson, Franklin Lakes, NY, USA) and centrifuged at 4000 r.p.m. for $5 \mathrm{~min}$ at $4{ }^{\circ} \mathrm{C}$ (Hettich Universal 32, Andreas Hettich GmbH \& Co. KG, Tuttlingen, Germany). The brain was dissected and one hemisphere was put in a falcon tube containing $50 \%$ acetonitrile in saline (4 $\mathrm{mL}$ ), and homogenized using a dispenser (IKA T18 B UltraTurrax, IKA-Werke GmbH \& Co KG, Staufen, Germany) before centrifugation at 4000 r.p.m. for $5 \mathrm{~min}$ at $4{ }^{\circ} \mathrm{C}$. The 
other hemisphere was counted for radioactivity for recovery calculations. Plasma and brain supernatant were separated from blood cells and brain precipitate, respectively.

About $1 \mathrm{~mL}$ of plasma was diluted with $2 \mathrm{~mL}$ of $0.15 \mathrm{M}$ hydrochloric acid and loaded onto a $\mathrm{tC}_{2}$ Sep-Pak cartridge, which was preactivated by elution with $3 \mathrm{~mL}$ of methanol and $6 \mathrm{~mL}$ of water, respectively. The cartridge was washed with 3 $\mathrm{mL}$ of water to collect the rest of the polar radioactive metabolites. The polar radioactive metabolite fraction was defined as the two combined fractions. Next, the $\mathrm{tC}_{2}$ Sep-Pak cartridge was eluted with $1.5 \mathrm{~mL}$ of methanol $(\mathrm{MeOH})$ and 2 $\mathrm{mL}$ of water to collect the mixture of nonpolar radioactive metabolites. About $2 \mathrm{~mL}$ of the brain supernatant was ultracentrifuged (Eppendorf 5417c, Eppendorf, Hamburg, Germany), and $1 \mathrm{~mL}$ was injected onto an HPLC system. All nonpolar metabolites and polar brain metabolites fractions were immediately analyzed using HPLC to determine the percentage of the intact $\left[{ }^{11} \mathrm{C}\right] 1$ or $\left[{ }^{11} \mathrm{C}\right] 2$. HPLC was performed on the Dionex Ultimate 3000 System station, equipped with $1 \mathrm{~mL}$ loop, with Phenomenex Gemini C18, 250 $\times 10 \mathrm{~mm}, 5 \mu \mathrm{m}$, column using gradient elution of acetonitrile $+0.1 \%$ TFA (D) and water $+0.1 \%$ TFA (F) in water. The HPLC gradient ran for 14 min decreasing the concentration of eluent $\mathrm{F}$ from $90 \%$ to $20 \%$ in $11 \mathrm{~min}, 2$ min with $20 \%$ of $\mathrm{F}$, and back to original setting $(90 \% \mathrm{~F})$ at flow $5 \mathrm{~mL} \cdot \mathrm{min}^{-1}$. All separated fractions of the brain supernatant were counted for radioactivity in a Wizard Gamma Counter 1470 or 2480 (Wallac, PerkinElmer, Waltham, MA, USA). The percentage of the intact tracer in the nonpolar plasma fractions was determined by the online radioactivity detection by HPLC analysis for $\left[{ }^{11} \mathrm{C}\right] 1$ or $\left[{ }^{11} \mathrm{C}\right] 2\left(R_{\mathrm{t}}=11.7 \mathrm{~min}\right)$. AUC, providing the percentage of the intact tracer and the metabolites, has been corrected for decay. Results are expressed as percentage of the intact tracer, polar metabolites, and nonpolar metabolites \pm standard deviation.

Metabolites Analysis (Spinal Cord). Healthy male Wistar rats $(330-360 \mathrm{~g})$ were injected with the tracer $\left[{ }^{11} \mathrm{C}\right]$ $1(32.8 \pm 8.6 \mathrm{MBq} ; 0.63 \pm 0.17 \mathrm{nmol} ; n=4)$ via the tail vein under isoflurane anesthesia $\left(2-2.5 \%\right.$ in $\left.1 \mathrm{~L} \cdot \mathrm{min}^{-1}\right)$. The rodents were sacrificed at 15 min postinjection for the tracer $\left[{ }^{11} \mathrm{C}\right] \mathbf{1}(n=4$ per time point). Whole spinal cord was collected via cutting the muscles and breaking the spine and was put in a falcon tube containing 50\% acetonitrile in saline $(2 \mathrm{~mL})$ and homogenized with a dispenser (IKA T18 B Ultra-Turrax, IKAWerke GmbH \& Co KG, Staufen, Germany) before centrifugation at 4000 r.p.m. for 2 min at ambient temperature (Eppendorf 5417c, Eppendorf, Hamburg, Germany). Spinal cord supernatant and precipitate were separated, and about 1.5 $\mathrm{mL}$ of precipitate was immediately analyzed using HPLC to determine the percentage of the intact $\left[{ }^{11} \mathrm{C}\right] 1$. HPLC ran on the Dionex Ultimate 3000 System station, equipped with $1 \mathrm{~mL}$ loop, with Phenomenex Gemini C18, $250 \times 10 \mathrm{~mm}, 5 \mu \mathrm{m}$, column using gradient elution of acetonitrile $+0.1 \%$ TFA (D) and water $+0.1 \%$ TFA $(F)$. The HPLC gradient ran for $14 \mathrm{~min}$ decreasing the concentration of eluent $\mathrm{F}$ from $90 \%$ to $20 \%$ in $11 \mathrm{~min}, 2$ min with $20 \%$ of F, and back to original setting ( $90 \%$ F) at flow $5 \mathrm{~mL} \cdot \mathrm{min}^{-1}$. The percentage of the intact tracer in the nonpolar plasma fractions was determined by the online radioactivity detection by HPLC analysis for $\left[{ }^{11} \mathrm{C}\right] \mathbf{1}\left(R_{\mathrm{t}}=11.6\right.$ $\mathrm{min})$. Area under the curve, providing the percentage of the intact tracer to the metabolites, has been corrected for decay. Results are expressed as percentage of the intact tracer and metabolites \pm standard deviation. All separated fractions (one fraction of $30 \mathrm{~s}$ ) of the spinal cord supernatant were counted for radioactivity in a Wizard Gamma Counter 1470 or 2480 (Wallac, PerkinElmer, Waltham, MA, USA).

LC-MS/MS Method. LC-MS/MS analysis was performed on a Jasco X-LC HPLC system (Easton, PA, USA) with an AB Sciex QTRAP 5500 mass spectrometer (Concorde, Ontario, Canada). The Jasco system consisted of two pumps (X-LC 3180PU), a degasser (X-LC 3080DG), a mixer (X-LC 3080MX), a column oven (X-LC 3080CO), and an auto sampler (X-LC3159AS). Data were collected with two data boxes (LV 2080-03 and LC-Net II/ACD).

A Kinetex Biphenyl C18 column $(2.6 \mu, 100$ A, $100 \times 2.10$ $\mathrm{mm}$; Phenomenex, Torrance, CA, USA) at $25^{\circ} \mathrm{C}$ was used for chromatographic separation. A gradient elution was used at a flow rate of $0.5 \mathrm{~mL} \cdot \mathrm{min}^{-1}$. The mobile phase consisted of a mixture of acetonitrile (C) and $0.1 \%$ formic acid in water according to the following scheme: $0 \mathrm{~min} 20 \% \mathrm{C}, 90 \% \mathrm{C}$ in 3.5 $\mathrm{min}, 90 \% \mathrm{C}$ for $3.6 \mathrm{~min}, 20 \% \mathrm{C}$ in $5 \mathrm{~min}$ at $25^{\circ} \mathrm{C}$. MS parameters: Turbolon Spray voltage was set at $5.5 \mathrm{kV}$, source temperature at $750{ }^{\circ} \mathrm{C}$. Based of full-scan MS and MS/MS spectra of each analyte, the most abundant fragment ions were selected, and the mass spectrometer was set to monitor the transitions of the precursors to the product ions as followed: $m / z 299.1 \rightarrow 255.1$ for the intact tracer, $m / z 315.1 \rightarrow 271.1$ for the hydroxylated metabolite, and $m / z 475.1 \rightarrow 299.1$ for the glucoronated metabolite.

PET Imaging. Dynamic PET imaging was performed on healthy male Wistar rats $(200-320$ g; $n=10)$ using Nanoscan small animal PET/CT and PET/MR scanners (Mediso Ltd., Budapest, Hungary) with identical PET components. The rats were anaesthetized with $3 \%$ and $1-2.5 \%$ isoflurane in oxygen $\left(1 \mathrm{~L} \cdot \mathrm{min}^{-1}\right)$ for induction and maintenance, respectively. Rats were positioned on the scanner bed, and respiratory rate was monitored during the entire time of scanning. A computed tomography (CT) or magnetic resonance imaging (MRI) scan was performed for 5 or $15 \mathrm{~min}$, respectively, followed by intravenous (i.v.) administration of $\left[{ }^{11} \mathrm{C}\right] \mathbf{1}(13.1 \pm 5.8 \mathrm{MBq}$; $0.14 \pm 0.06 \mathrm{nmol} ; n=4)$ or of $\left[{ }^{11} \mathrm{C}\right] 2(14.7 \pm 1.5 \mathrm{MBq} ; 0.37$ $\pm 0.24 \mathrm{nmol} ; n=3)$ via tail vein cannula at the start of a dynamic PET scan of $60 \mathrm{~min}$. PET data were normalized and corrected for scatter, randomization, attenuation, decay, and dead time. List-mode PET data were rebinned in 18 successive frames: $4 \times 5,4 \times 10,2 \times 30,3 \times 60,2 \times 300,1 \times 600,1 \times$ 900 , and $1 \times 1200 \mathrm{~s}$, which were reconstructed using a fully three-dimensional reconstruction algorithm (Tera-TomoTM) using four iterations and six subsets, resulting in an isotropic $0.4 \mathrm{~mm}$ voxel dimension. Static reconstruction was also performed on the total duration of the scan $(60 \mathrm{~min})$. Images were analyzed using the freely available AMIDE software (A Medical Image Data Examiner; version 1.0.4), whereas images in Figure 6 are made using VivoQuant (version 3.0, InVicro, Boston, MA, USA). Regions of interest (ROI) were drawn manually around whole brain (ellipsoid) and spinal cord (elliptic cylinder). Results are expressed as standardized uptake values (SUVs), and error bars indicate standard deviation using Graph Pad Prism (Version 5.02, Graph Pad Software Inc., La Jolla, CA, USA).

For blocking experiments, rats were injected with the natural heptapeptide $\mathrm{SP}_{1-7}$ or 1 or $\mathbf{2}$, depending on the investigated PET tracer. The $\mathrm{SP}_{1-7}$ was diluted in DMSO and then further diluted with saline to the final concentration (5\% DMSO). Peptide was injected intraperitoneally (i.p.) (185 nmol $\left.\cdot \mathrm{kg}^{-1}\right)$, according to previous experiments by Jonsson, ${ }^{1} 15 \mathrm{~min}$ prior to 
Scheme 1. Radiosynthesis of $\mathrm{SP}_{1-7}$ Carbamate Analogues $\left[{ }^{11} \mathrm{C}\right] 1$ and $\left[{ }^{11} \mathrm{C}\right] 2$
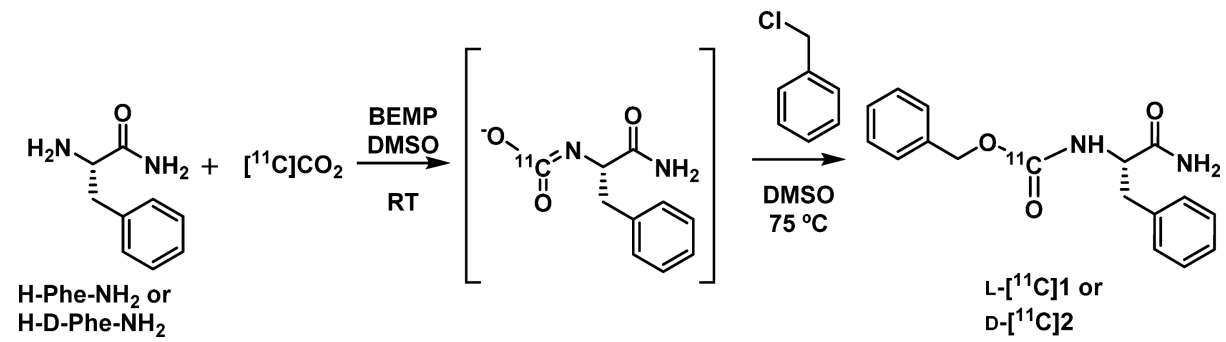

tracer $\left[{ }^{11} \mathrm{C}\right] \mathbf{1}$ administration (tracer administration per rat: $22.3 \pm 0.5 \mathrm{MBq} ; 0.30 \pm 0.01 \mathrm{nmol} ; n=2$ ). Compound 1 was dissolved in $\mathrm{EtOH}$ and further diluted with saline to the final concentration (20\% EtOH). Compound 1 was injected slowly i.v. in the tail vein $\left(3 \mu \mathrm{mol} \cdot \mathrm{kg}^{-1}\right)$, according to previous experiments by Fransson, ${ }^{35} 3$ and 20 min prior to tracer $\left[{ }^{11} \mathrm{C}\right] 1$ administration (tracer administration per rat: $34.0 \pm 10.8$ $\mathrm{MBq} ; 0.55 \pm 0.14 \mathrm{nmol} ; n=3$ for $3 \mathrm{~min}$; and $16.4 \pm 4.3 \mathrm{MBq}$; $0.22 \pm 0.04 \mathrm{nmol} ; n=2$ for $20 \mathrm{~min}$ ). Same dose and formulation conditions applied for compound 2, with the exception that it was injected only $3 \mathrm{~min}$ prior to tracer $\left[{ }^{11} \mathrm{C}\right] 2$ administration (tracer administration per rat: $16.8 \pm 10.1$ $\mathrm{MBq} ; 0.25 \pm 0.15 \mathrm{nmol} ; n=2)$.

\section{RESULTS}

Prediction Models. The characteristics of the $\mathrm{SP}_{1-7}$ peptidomimetics for brain penetration were anticipated prior to synthesis and radiolabeling. ACD/Laboratories Percepta's Drug profiler and BBB module report confirmed optimal physiochemical and ADME profile, as well as brain penetration sufficient for CNS activity (Supporting Information). CNS PET MPO algorithm was calculated following the publication of Zhang et al. ${ }^{31}$ and displayed a value of 3.6, which is in the desirable range for BBB penetration (Supporting Information).

Chemistry. Reference compounds $((S)$-benzyl (1-amino-1oxo-3-phenylpropan-2-yl)carbamate 1 and $((R)$-benzyl (1amino-1-oxo-3-phenylpropan-2-yl)carbamate 2) were synthesized according to patented procedure ${ }^{36}$ in a one-step amidation reaction (Supporting Information Scheme 1) from a commercially available 2-(((benzyloxy) carbonyl)amino)-3phenylpropanoic acids. Reference compounds were further characterized according to Fransson et al. ${ }^{35}$ Overnight amidation at ambient temperature followed by extraction and precrystallization in ice-cold $n$-hexane yielded L-stereoisomer 1 in $80 \%$ yield and D-stereoisomer 2 in $55 \%$ yield.

Radiochemistry. The general synthesis toward the $\mathrm{SP}_{1-7}$ carbamate analogues $\left[{ }^{11} \mathrm{C}\right] \mathbf{1}$ and $\left[{ }^{11} \mathrm{C}\right] \mathbf{2}$ is outlined in Scheme 1. The synthesis involved two steps: direct $\left[{ }^{11} \mathrm{C}\right] \mathrm{CO}_{2}$ trapping at ambient temperature and ${ }^{11} \mathrm{C}$-carboxybenzylation at elevated temperature. The preparation of $\mathrm{SP}_{1-7}$ carbamate analogue $\left[{ }^{11} \mathrm{C}\right] 1 /\left[{ }^{11} \mathrm{C}\right] 2$ was achieved without the isolation of the synthetic intermediate in a one-pot reaction to establish an efficient procedure for the desired product (Supporting Information Table 1). In order to optimize this procedure, the following parameters have been thoroughly investigated: amount of reagents and solvent, reaction time, and helium flow. These parameters were changed systematically one by one per experiment.

Trapping of cyclotron-produced $\left[{ }^{11} \mathrm{C}\right] \mathrm{CO}_{2}$ was $>90 \%$, when $\left[{ }^{11} \mathrm{C}\right] \mathrm{CO}_{2}$ was bubbled thought the precursor solution in dry DMSO with the aid of 3.5-5.0 equiv of 2-tert-butylimino-2- diethylamino-1,3-dimethylperhydro-1,3,2-diazaphosphorine (BEMP), which served as trapping reagent and a catalyst for the carboxylation reaction. The ${ }^{11} \mathrm{C}$-carboxybenzylation to the desired product was achieved in high radiochemical yield (>85\%; Supporting Information Table 1), determined by analytical HPLC, using 4-5 equiv of benzyl chloride, dissolved in DMSO, at $75{ }^{\circ} \mathrm{C}$ under helium stirring $\left(10 \mathrm{~mL} \cdot \mathrm{min}^{-1}\right)$. Excellent conversion rates were attained for both reaction times of 5 and $10 \mathrm{~min}$, whereas time of $5 \mathrm{~min}$ was selected to decrease the total synthesis time. The volume of DMSO was increased to $300 \mu \mathrm{L}$ for a smoother automation of the synthesis procedure. Importantly, $N$-benzylation or other significant side products were not observed during the ${ }^{11} \mathrm{C}$ carboxybenzylation reaction (Supporting Information Figure 1).

The next step, purification of the PET-tracer was achieved using a reverse-phase C18 semipreparative HPLC (Supporting Information Figures 2 and 3). Subsequent reformulation toward an injectable solution provided $\left[{ }^{11} \mathrm{C}\right] 1$ (5.1 \pm 2.2 GBq) in a radiochemical purity of $>99 \%$ and $A_{\mathrm{M}}$ of $93.2 \pm 46.9$ $\mathrm{GBq} \cdot \mu \mathrm{mol}^{-1}$ in $23-29 \mathrm{~min}$ with an overall $\mathrm{RCY}$ of $27.9 \pm$ $10.9 \%$ (corrected for decay; $n=10$ ) formulated in an i.v. injectable solution containing $10 \% \mathrm{EtOH}$ in saline, ready for in vivo experiments.

In the same manner, we performed the reaction with H-DPhe- $\mathrm{NH}_{2}$ as precursor. As expected, the D-isomer displayed the same properties, and the radiosynthesis of $\left[{ }^{11} \mathrm{C}\right] 2$ provided an isolated noncorrected yield of $3.9 \pm 1.9 \mathrm{GBq}(n=5)$ in a radiochemical purity of $>99 \%$ and $A_{\mathrm{M}}$ of $69.4 \pm 11.4$ $\mathrm{GBq} \cdot \mu \mathrm{mol}^{-1}(n=4)$ in $26-29 \mathrm{~min}(n=5)$ with an overall RCY of $25.5 \pm 9.7 \%$ (corrected for decay; $n=5$ ) formulated in an i.v. injectable solution (10\% $\mathrm{EtOH}$ in saline).

Ex Vivo Biodistribution. In order to assess the brain and spinal cord penetration potential of $\left[{ }^{11} \mathrm{C}\right] 1$, an ex vivo biodistribution study was performed. Healthy male Wistar rats were injected with $\left[{ }^{11} \mathrm{C}\right] 1(25.8 \pm 7.6 \mathrm{MBq} ; 0.74 \pm 0.21$ nmol; $n=16$ ) and were analyzed for biodistribution at 5,15 , 30 , and $60 \mathrm{~min}$ postinjection (p.i.) (Figure 2). $\left[{ }^{11} \mathrm{C}\right] \mathbf{1}$ was cleared via kidneys and liver and showed moderate uptake in well-perfused organs, like lungs and heart. Highest uptake was observed after $5 \mathrm{~min}$ in the brain regions (large brain, cerebellum, brain stem) and spinal cord, showing rapid penetration and $\mathrm{BBB}$ crossing of the $\mathrm{SP}_{1-7}$ peptidomimetic. At later time points, we observed a better retention of the $\left[{ }^{11} \mathrm{C}\right] \mathbf{1}$ tracer in the spinal cord compared to the brain and the perfused organs.

From the data obtained, organ of interest-to-blood ratios were also calculated (Figure 3A). The brain-to-blood ratios were 1.24-1.39 and spinal cord-to-blood ratios were $0.82-$ 0.88 for $\left[{ }^{11} \mathrm{C}\right] \mathbf{1}$. 


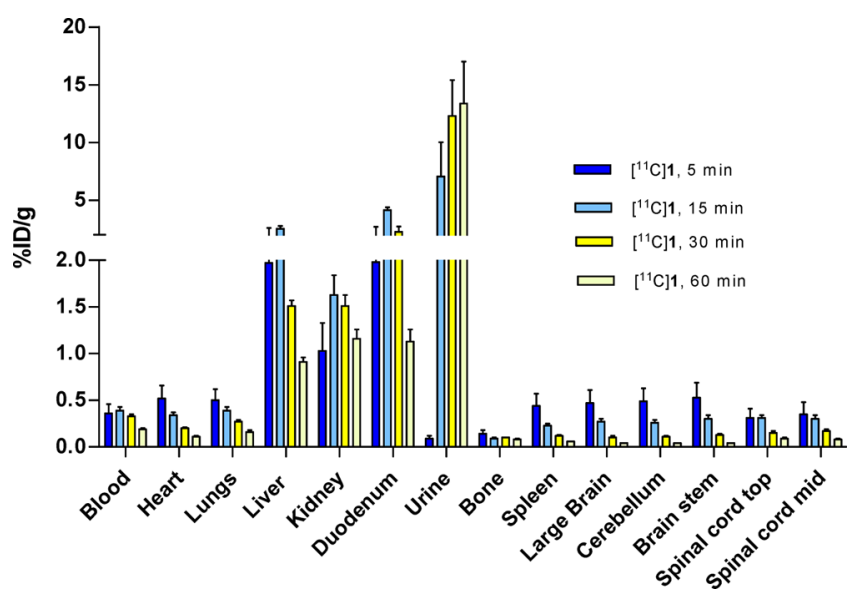

Figure 2. Biodistribution of $\left[{ }^{11} \mathrm{C}\right] \mathbf{1}$ at $5,15,30$, and $60 \mathrm{~min}$ postinjection (p.i.) in healthy male Wistar rats $(n=4$ per time point $)$ following i.v. administration of $25.8 \pm 7.6 \mathrm{MBq}(0.74 \pm 0.21 \mathrm{nmol} ; n$ $=16)$ of $\left[{ }^{11} \mathrm{C}\right] \mathbf{1}$ via the tail vein under isoflurane anesthesia $(2-2.5 \%$ in $\left.1 \mathrm{~L} \cdot \mathrm{min}^{-1}\right)$. Values are expressed in $\% \mathrm{ID} / \mathrm{g} \pm \mathrm{SEM}$.

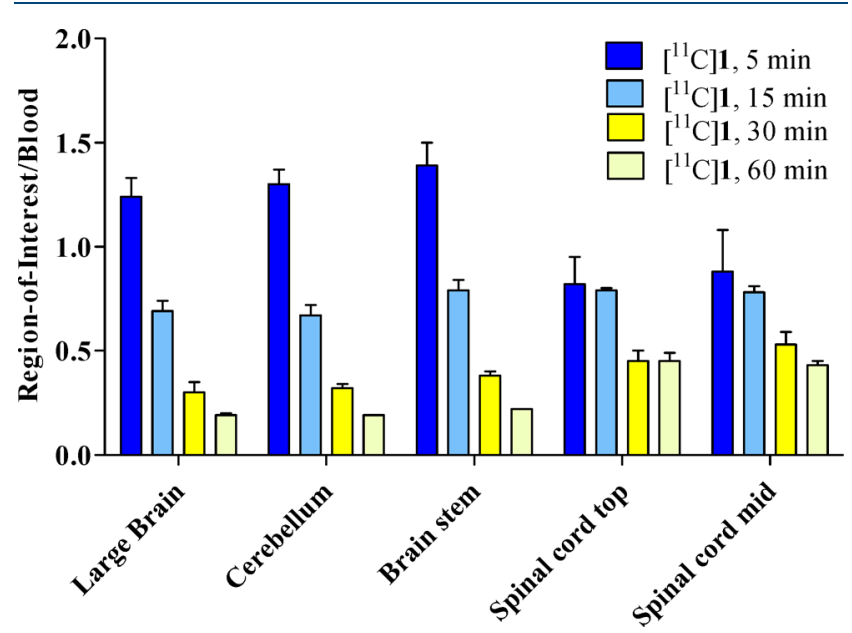

Figure 3. (A) Organs-to-blood ratio of $\left[{ }^{11} \mathrm{C}\right] 1$ at $5,15,30$, and 60 $\min (n=4$ per time point). Columns show the region-of-interest to blood ratio \pm SEM.

Metabolite Analysis (L- $\left.\left[{ }^{11} \mathrm{C}\right] 1\right)$. In vivo stability of $\left[{ }^{11} \mathrm{C}\right] \mathbf{1}$ was determined by metabolite analysis in healthy male Wistar rats $(n=4$ per time point). Rats were injected i.v. with the radiotracer $\left[{ }^{11} \mathrm{C}\right] 1(27.3 \pm 7.3 \mathrm{MBq} ; 0.50 \pm 0.22 \mathrm{nmol} ; n=$ 12) and sacrificed at 5,15 , and $45 \mathrm{~min}$ p.i. followed by blood sample collection and brain dissection. Analysis of the plasma revealed mediocre stability of the tracer with 52, 15, and $11 \%$ of intact tracer after 5, 15, and $45 \mathrm{~min}$, respectively, suggesting extensive metabolic degradation (Table 1). HPLC analysis of the plasma showed the presence of one major metabolite of $\left[{ }^{11} \mathrm{C}\right] \mathbf{1}$ after $45 \mathrm{~min}$. This major metabolite had a retention time of $12.7 \mathrm{~min}$ and constituted more than $67 \%$ of the nonpolar metabolites (Figure 4). Radioactivity recovery of the blood samples was $99.1 \pm 0.3,70.0 \pm 2.2$, and $65.5 \pm 3.7 \%$ at 5,15 , and $45 \mathrm{~min}$, respectively. The Sep-Pak cartridge stickiness at later time points was inevitable, despite additional employment of $\mathrm{MeOH}$.

In brain supernatant, the percentage of intact tracer in the nonpolar fraction was $>99.9 \%$ at $5 \mathrm{~min}$ and $97 \%$ after 15 or 45 min (Figure 4D). Radioactivity extraction of the brain supernatant samples was $77.1 \pm 5.2,71.5 \pm 15.7$, and 63.0 $\pm 5.9 \%$ at 5,15 , and $45 \mathrm{~min}$, respectively. These data confirms rapid penetration and stability of the $\left[{ }^{11} \mathrm{C}\right] \mathbf{1}$ tracer in brain.

Additionally, in vivo stability of $\left[{ }^{11} \mathrm{C}\right] 1$ in spinal cord was preliminary assessed by metabolite analysis in healthy male Wistar rats $(n=4$ per time point). Rats were injected i.v. with the radiotracer $\left[{ }^{11} \mathrm{C}\right] \mathbf{1}(32.8 \pm 8.6 \mathrm{MBq} ; 0.63 \pm 0.17 \mathrm{nmol} ; n=$ 4) and sacrificed at $15 \mathrm{~min}$ p.i. followed by spinal cord dissection. Unfortunately, the percentage of the intact tracer in the spinal cord supernatant was possible to be assessed only for one rat (Supporting Information), where results indicate that $\left[{ }^{11} \mathrm{C}\right] \mathbf{1}$ is stable in spinal cord after $15 \mathrm{~min}$, with a trace unidentified metabolite 2 (Supporting Information Figure 4).

Metabolite Analysis ( $D-\left[{ }^{11} C\right] 2$ ). In order to improve the bioavailability of the tracer we investigated the effect of substitution of L-phenylalanine to D-configuration. We synthesized the $\mathrm{D}$-variant $\left[{ }^{11} \mathrm{C}\right] \mathbf{2}$ and examined the in vivo stability by metabolite analysis in healthy male Wistar rats $(n=$ 3 per time point). The rodents were injected i.v. with $\left[{ }^{11} \mathrm{C}\right] 2$ tracer $(32.4 \pm 3.4 \mathrm{MBq} ; 1.80 \pm 0.19 \mathrm{nmol} ; n=9)$ and rats were sacrificed at 5,15 , and $45 \mathrm{~min} \mathrm{p.i.} \mathrm{followed} \mathrm{by} \mathrm{blood}$ collection and brain dissection. Plasma analysis revealed improved stability of the tracer with 80,49 , and $37 \%$ of intact tracer after 5, 15, and $45 \mathrm{~min}$, respectively (Table 2). Radioactivity recovery of the blood samples was $95-99 \%$ at all time points. HPLC analysis of nonpolar fraction revealed three unidentified metabolites (Figure 4E-G and Table 2).

In brain supernatant, the percentage of intact $\mathrm{D}-\left[{ }^{11} \mathrm{C}\right] 2$ tracer in the nonpolar fraction was $>96 \%$ after 5,15 , and $45 \mathrm{~min}$ (Figure 4B,H). Radioactivity extraction of the brain supernatant samples was $58.8 \pm 13.7,55.1 \pm 22.0$, and $63 \pm 13.3 \%$ at 5, 15, and $45 \mathrm{~min}$, respectively.

LC-MS/MS Method. A product ion scan was performed for $\mathbf{1}$ to determine high intensity mass fragments in a multiple reaction monitoring (MRM) method by LC-MS/MS experiments. The transition of 299.1 to $255.1 \mathrm{~m} / z$ was chosen where the fragments corresponded to the intact parent ion and a loss of carboxylic fragment, and the transition of 315.1 to $271.1 \mathrm{~m} /$ $z$ was chosen where the fragments corresponded to the hydroxylated parent ion and a loss of carboxylic fragment. Nonpolar plasma fractions, after 5 and $15 \mathrm{~min}$ p.i., were analyzed demonstrating a trace amount of $\mathbf{2}$ (Supporting

Table 1. Metabolite Analysis of $\left[{ }^{11} \mathrm{C}\right] 1$ in Plasma, Brain, and Spinal Cord Supernatant

\begin{tabular}{|c|c|c|c|c|c|c|c|}
\hline & \multicolumn{3}{|c|}{ plasma } & \multicolumn{3}{|c|}{ brain } & \multirow{2}{*}{$\frac{\text { spinal cord }}{15 \min [\%]}$} \\
\hline & $5 \min [\% ; \mathrm{SD}]$ & $15 \min [\% ; \mathrm{SD}]$ & $45 \min [\% ; \mathrm{SD}]$ & $5 \min [\% ; \mathrm{SD}]$ & $15 \min [\% ; \mathrm{SD}]$ & $45 \min [\% ; \mathrm{SD}]$ & \\
\hline intact tracer & $52.3 \pm 11.3$ & $15.2 \pm 7.9$ & $10.9 \pm 3.0$ & $>99.9$ & $97.3 \pm 0.6$ & $96.7 \pm 4.5$ & 97.6 \\
\hline nonpolar metabolite 1 & $7.8 \pm 5.4$ & $7.9 \pm 2.4$ & $7.7 \pm 2.9$ & & $0.9 \pm 0.6$ & $1.6 \pm 3.2$ & \\
\hline nonpolar metabolite 2 & & & $1.1 \pm 1.1$ & & & & \\
\hline nonpolar metabolite 3 & $34.3 \pm 5.0$ & $40.8 \pm 4.4$ & $40.0 \pm 1.7$ & & $1.8 \pm 0.2$ & $1.6 \pm 3.2$ & 2.4 \\
\hline polar metabolites & $5.2 \pm 1.1$ & $6.1 \pm 0.4$ & $5.7 \pm 0.3$ & & & & \\
\hline
\end{tabular}




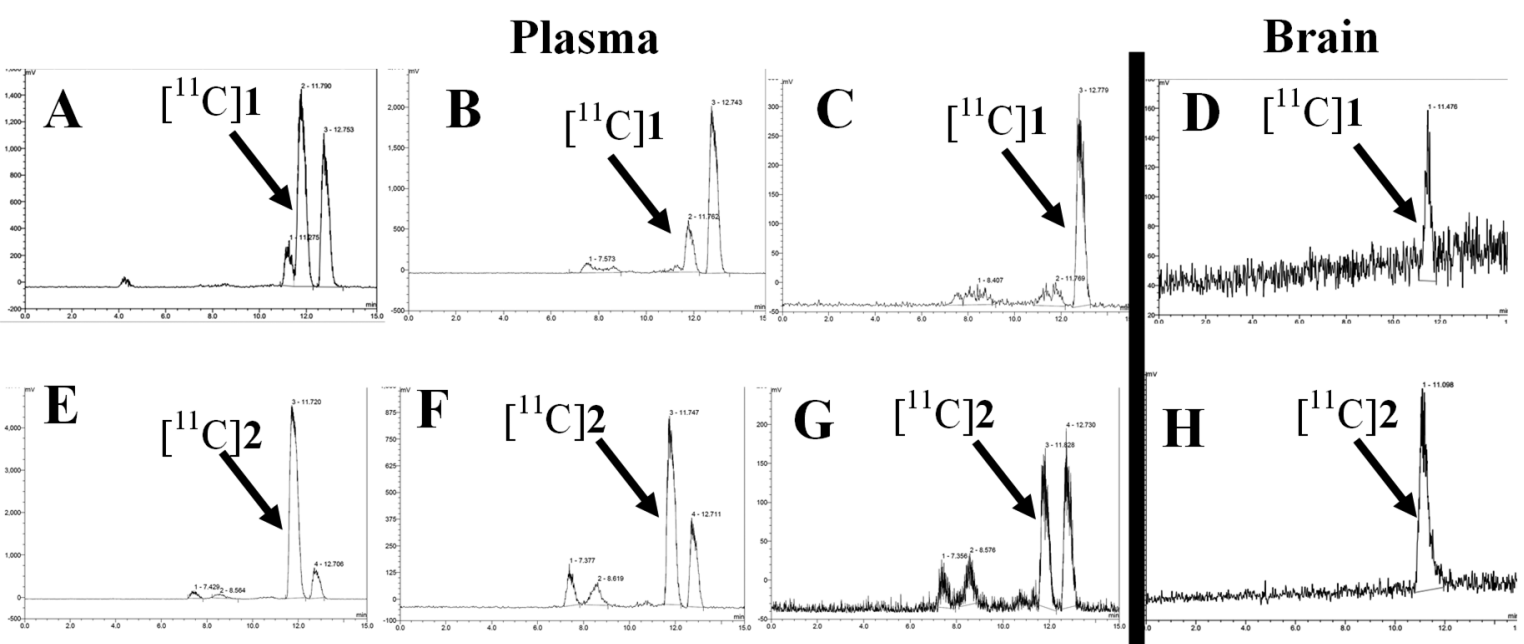

Figure 4. Metabolites radiochromatograms of the plasma nonpolar fraction after (A) 5 min, (B) 15 min, and (C) 45 min after L- $\left[{ }^{11} \mathrm{C}\right] \mathbf{1}$ injection; (E) $5 \mathrm{~min},(\mathrm{~F}) 15 \mathrm{~min}$, and (G) $45 \mathrm{~min}$ after $\mathrm{D}-\left[{ }^{11} \mathrm{C}\right] 2$ injection. Intact $\mathrm{L}-\left[{ }^{11} \mathrm{C}\right] \mathbf{1}$ and $\mathrm{D}-\left[{ }^{11} \mathrm{C}\right] 2$ have a retention time of $11.7 \mathrm{~min}$. Radiochromatograms of the total fraction of brain supernatant after 5 min showing the presence of intact tracer: $(\mathrm{D}) \mathrm{L}-\left[{ }^{11} \mathrm{C}\right] 1\left(R_{\mathrm{t}}\right.$ of $\left.11.5 \mathrm{~min}\right)$; (H) $\mathrm{D}-\left[{ }^{11} \mathrm{C}\right] 2\left(\mathrm{R}_{\mathrm{t}}\right.$ of $\left.11.1 \mathrm{~min}\right)$. HPLC data has been corrected for decay.

Table 2. Metabolite Analysis of $\mathrm{D}-$ Isomer $\left[{ }^{11} \mathrm{C}\right] 2$ in Plasma and Brain Supernatant

\begin{tabular}{|c|c|c|c|c|c|c|}
\hline & \multicolumn{3}{|c|}{ plasma } & \multicolumn{3}{|c|}{ brain } \\
\hline & $5 \min [\% ; \mathrm{SD}]$ & $15 \min [\% ; \mathrm{SD}]$ & $45 \min [\% ; \mathrm{SD}]$ & $5 \min [\% ; S D]$ & $15 \min [\% ; \mathrm{SD}]$ & $45 \min [\% ; \mathrm{SD}]$ \\
\hline intact tracer & $79.6 \pm 2.3$ & $49.2 \pm 2.0$ & $36.6 \pm 1.7$ & $96.4 \pm 6.3$ & $96.4 \pm 5.2$ & $>99.9$ \\
\hline nonpolar metabolite 1 & $2.6 \pm 0.2$ & $9.8 \pm 0.8$ & $10.5 \pm 4.8$ & $3.6 \pm 6.3$ & $3.6 \pm 5.2$ & \\
\hline nonpolar metabolite 2 & $1.8 \pm 0.6$ & $9.5 \pm 1.3$ & $7.2 \pm 3.0$ & & & \\
\hline nonpolar metabolite 3 & $11.3 \pm 1.1$ & $20.9 \pm 1.5$ & $33.6 \pm 0.2$ & & & \\
\hline polar metabolites & $3.5 \pm 0.5$ & $5.6 \pm 0.9$ & $7.3 \pm 2.0$ & & & \\
\hline
\end{tabular}
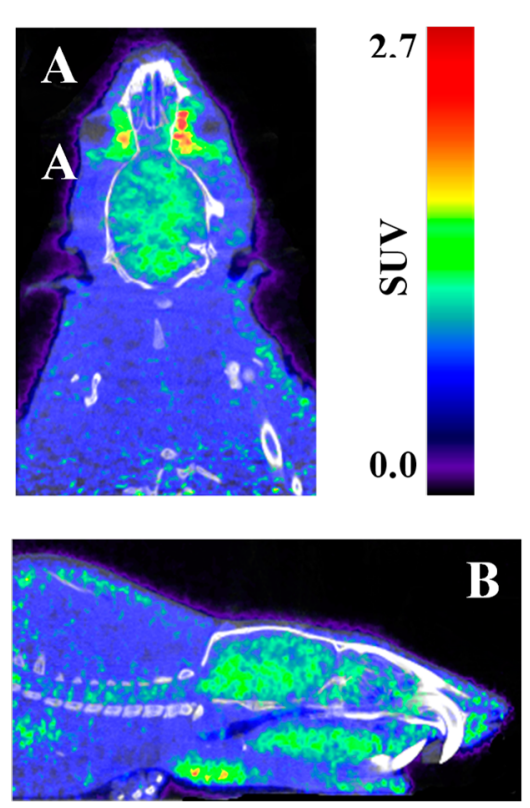

C: Spinal Cord: $\left[{ }^{11} \mathrm{C}\right] 1$

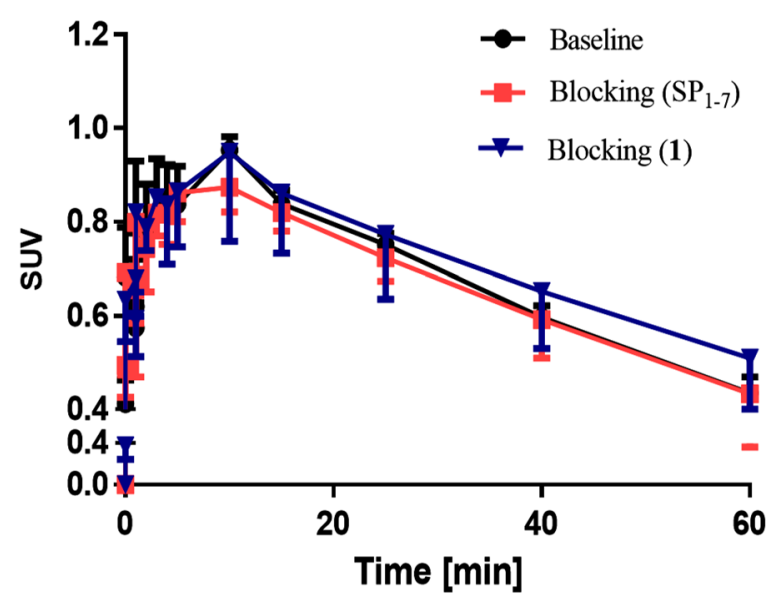

Figure 5. Static reconstruction of the PET image scans in healthy male Wistar rat (Rat 2) with tracer $\left[{ }^{11} \mathrm{C}\right] \mathbf{1}(20 \mathrm{MBq}$ i.v. injection via tail vein; $3 \%$ and $1-2.5 \%$ isoflurane in oxygen $\left(1 \mathrm{~L} \cdot \mathrm{min}^{-1}\right)$ for induction and maintenance). (A) PET/CT between $0-60$ min coronal image. (B) PET/CT between 0-60 min sagittal image. (C) Time-activity curves (TACs) of $\left[{ }^{11} \mathrm{C}\right] \mathbf{1}$ expressed as SUV \pm SD. TACs of nonblocking (black line) and blocking conditions (colored lines): natural $\mathrm{SP}_{1-7}$ administered 15 min before $\left[{ }^{11} \mathrm{C}\right] \mathbf{1}$ (red line; $n=2$ ) and compound 120 min prior to tracer injection (blue line; $n=2$ ).

Information Figure 5; blue trace) and two mass peaks of 315.1 $m / z$ (Supporting Information Figure 5; red trace) corresponding to the hydroxylated parent ion.
Additionally, the transition of 475.1 to $299.1 \mathrm{~m} / z$ was chosen to detect the glucoronated parent ion and the intact parent ion. Rat was pretreated with cold nonradiolabeled 1, injected 5 min before PET scan as a blocker, where nonpolar 

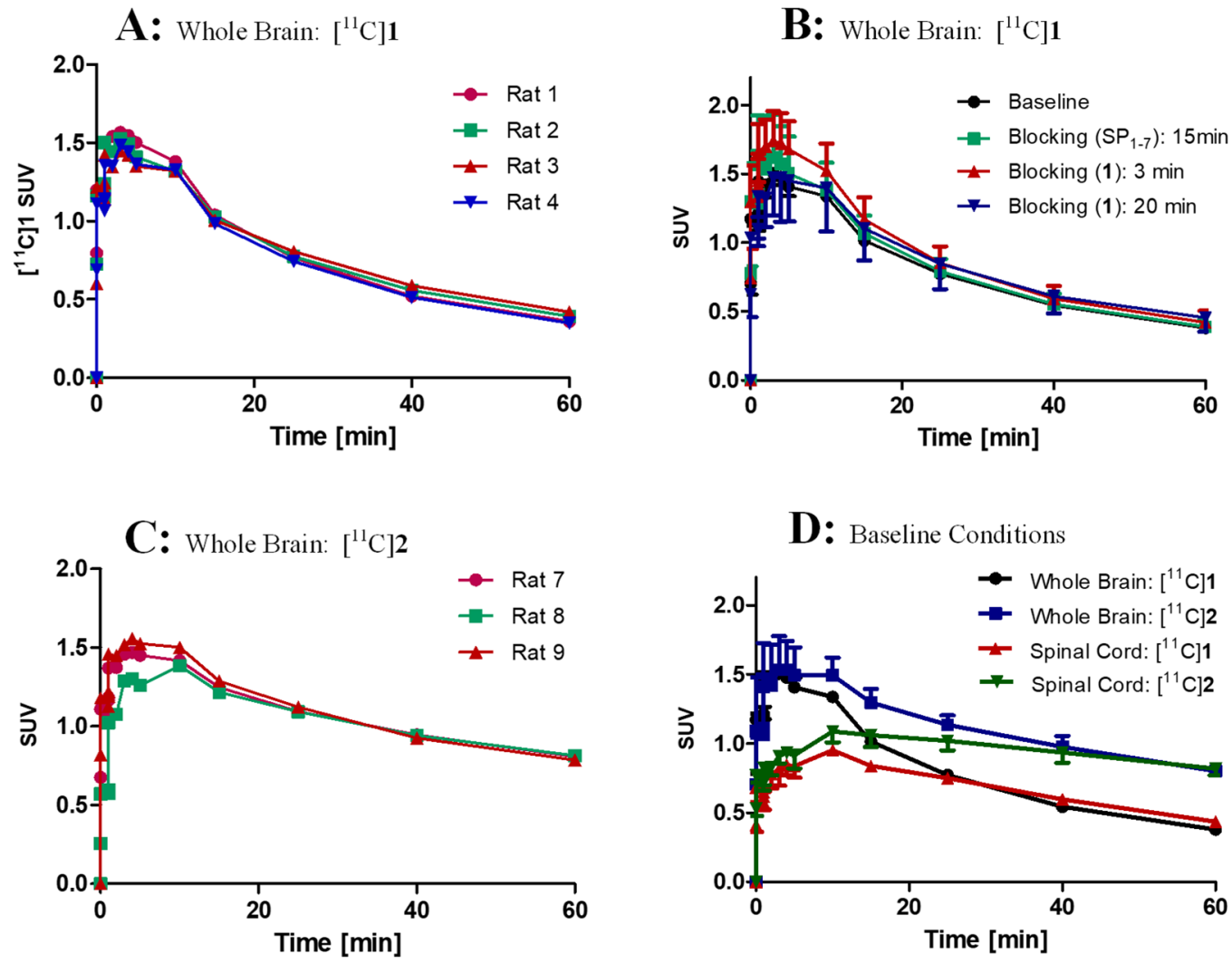

E: Whole Brain

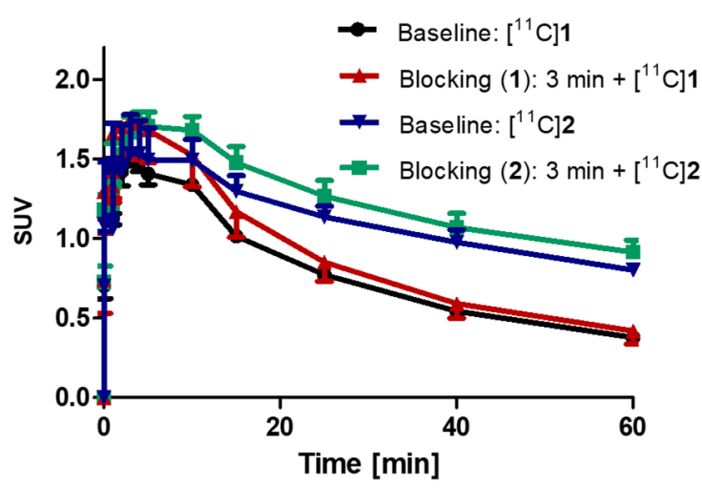

F: Spinal Cord

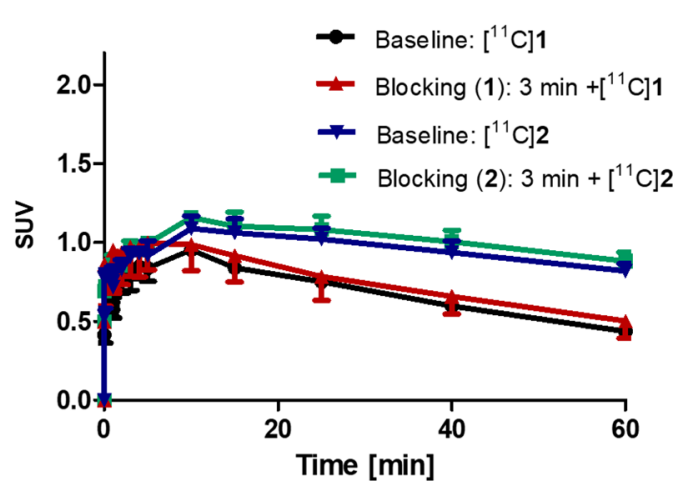

Figure 6. Time-activity curves (TACs) of $\left[{ }^{11} \mathrm{C}\right] 1$ and $\left[{ }^{11} \mathrm{C}\right] 2$ in healthy male Wistar rats expressed in SUV \pm SD (region of interest around the brain and spinal cord were drawn manually). (A) TACs of whole brain with tracer $\left[{ }^{11} \mathrm{C}\right] \mathbf{1}$. (B) TACs of nonblocking and blocking conditions with tracer $\left[{ }^{11} \mathrm{C}\right] 1$. (C) TACs of whole brain with tracer $\left[{ }^{11} \mathrm{C}\right] 2$. (D) TACs of whole brain regions and spinal cord (top part) of $\left[{ }^{11} \mathrm{C}\right] 1$ or $\left[{ }^{11} \mathrm{C}\right] \mathbf{2}$. $(\mathrm{E})$ TACs under a baseline and self-blocking conditions for $\left[{ }^{11} \mathrm{C}\right] 1$ and $\left[{ }^{11} \mathrm{C}\right] 2$ in whole brain. $(\mathrm{F})$ TACs under a baseline and self-blocking conditions for $\left[{ }^{11} \mathrm{C}\right] \mathbf{1}$ and $\left[{ }^{11} \mathrm{C}\right] \mathbf{2}$ in spinal cord (top part).

plasma sample indeed confirmed the glucorinated metabolite after $60 \mathrm{~min}\left[{ }^{11} \mathrm{C}\right] \mathbf{1}$ p.i. (Supporting Information Figure 5, green trace). Furthermore, using this transition the nonpolar plasma samples from in vivo stability study of $\left[{ }^{11} \mathrm{C}\right] 2$ were reanalyzed, confirming the postulated metabolites (hydroxylation, oxidative deamination, and subsequent glucoronidation) (Supporting Information Scheme 2).

PET Imaging. Dynamic PET imaging was carried out in healthy rats with $\left[{ }^{11} \mathrm{C}\right] 1$ and $\left[{ }^{11} \mathrm{C}\right] 2$ tracers (Figure 5). The time-activity curves (TACs) of the PET imaging showing SUVs over time are presented in Figure 6. Under baseline conditions, $\left[{ }^{11} \mathrm{C}\right] 1$ scan revealed good uptake in the brain, reaching a maximum of $1.50 \pm 0.05 \mathrm{SUV}(n=4)$ at $3 \mathrm{~min}$ p.i., followed by a rapid clearance within $60 \mathrm{~min} .\left[{ }^{11} \mathrm{C}\right] 1$ showed consistent uptake in the brain with no variation between different rats (Figure 6A). In the spinal cord (Figure 6F) the maximum uptake was at $10 \mathrm{~min}$ p.i. and reached $0.95 \pm 0.03$ SUV $(n=4)$.

In order to verify the specific uptake in brain, blocking experiments were performed. Pretreatment with natural $\mathrm{SP}_{1-7}$ (15 min, i.p., $\left.185 \mathrm{nmol} \cdot \mathrm{kg}^{-1}\right)$ or cold compound 1 (20 min prior to tracer injection, i.v., $3 \mu \mathrm{mol} \cdot \mathrm{kg}^{-1}$ ) did not block brain uptake. Although, when 1 was injected 3 min prior to tracer injection (i.v., $3 \mu \mathrm{mol} \cdot \mathrm{kg}^{-1}$ ), we noticed an increase in the SUV up to 2.0 at $3 \mathrm{~min}$. Despite our efforts to block brain uptake $\left[{ }^{11} \mathrm{C}\right] \mathbf{1}$, pretreatment did not measurably decrease radiotracer uptake resulting in similar uptake pattern for all scans (Figure $6 \mathrm{~B}, \mathrm{E})$. 
In the spinal cord, pretreatment with the natural $\mathrm{SP}_{1-7}$ showed moderate blocking ( 0.95 SUV baseline condition vs 0.87 SUV block) (Figure 5C, black vs red line). However, selfblocking with 1 at 3 or 20 min prior to tracer injection did not show any blocking (Figure 5C, blue line).

The uptake pattern of ${ }_{\mathrm{D}}-\left[{ }^{11} \mathrm{C}\right] 2$ in brain and spinal cord was different compared to L- $\left[{ }^{11} \mathrm{C}\right] 1$. At early time points (before 5 $\mathrm{min}$ ) the level of uptake was comparable between the two tracer, but at later time points $\mathrm{D}-\left[{ }^{11} \mathrm{C}\right] 2$ displayed slower clearance (SUV difference of app. 0.4 at $60 \mathrm{~min}$; Figure 6D, blue and green lines) and higher retention in brain and spinal cord. Self-blocking with compound 2 (3 min prior TOI, i.v., 3 $\left.\mu \mathrm{mol} \cdot \mathrm{kg}^{-1}\right)$ did not show any blocking effect in brain and spinal cord (brain, peak uptake at $3 \mathrm{~min}$, SUV baseline 1.5 vs block 1.7; spinal cord, peak uptake at $10 \mathrm{~min}$, SUV baseline 0.95 vs block 1.0) (Figure 6E,F).

\section{DISCUSSION}

The dipeptide $\mathrm{H}$-Phe-Phe- $\mathrm{NH}_{2}$ has been previously recognized as a small molecule ligand for the $\mathrm{SP}_{1-7}$ binding site with intriguing effect on neuropathic pain after central administration in rats. Herein, we introduce two $\mathrm{SP}_{1-7}$ carbon-11 labeled benzylacarbamate peptidomimetics, $\mathrm{L}_{-}\left[{ }^{11} \mathrm{C}\right] \mathbf{1}$ and its Danalogue $\left[{ }^{11} \mathrm{C}\right] 2$, derived from the lead dipeptide and their preliminary in vivo and ex vivo evaluation. In particular, we exploited two carbon-11 labeled $\mathrm{SP}_{1-7}$ ligands as radiotracers for a new target for PET imaging.

To facilitate the discovery of novel CNS PET ligands and to confirm the rationale for the PET ligand discovery process. we employed a novel tool CNS PET MPO and commercial in silico prediction platform. Both models supported the brain penetration. and consequently, the carbon-11 labeled $\mathrm{SP}_{1-7}$ peptidomimetics L- $\left[{ }^{11} \mathrm{C}\right] \mathbf{1}$ and $\mathrm{D}-\left[{ }^{11} \mathrm{C}\right] \mathbf{2}$ were successfully accomplished in an automated radiosynthesis with excellent yields, purities. and molar activities.

Even though the in vitro plasma stability and permeability assay of L-1 have been reported, in vivo evaluation is eagerly awaited. Initial in vivo biodistribution study of $\left[{ }^{11} \mathrm{C}\right] \mathbf{1}$ in healthy rats displayed desired uptake in large brain, cerebellum. and brain stem, as well as in spinal cord.

The metabolic stability of the $\left[{ }^{11} \mathrm{C}\right] \mathbf{1}$ was less optimal with fast degradation in the plasma, generally known for peptides. However, in the brain and spinal cord. $\left[{ }^{11} \mathrm{C}\right] \mathbf{1}$ showed high stability with more than $95 \%$ of intact tracer, suggesting that the degradation of $\left[{ }^{11} \mathrm{C}\right] \mathbf{1}$ is mainly due to the peptidase and proteases present in the blood. This claim is further supported by the significant increase of plasma stability when the L-Phe for its $\mathrm{D}$-isomer $\left(\left[{ }^{11} \mathrm{C}\right] 2\right)$. On a positive note. the $\left[{ }^{11} \mathrm{C}\right] \mathbf{1}$ metabolites did not cross the BBB or the BSCB, which support the potential of the molecule as a PET tracer. The metabolite data for for L- and D-carbamate tracers $\left(\left[{ }^{11} \mathrm{C}\right] \mathbf{1}\right.$ and $\left.\left[{ }^{11} \mathrm{C}\right] \mathbf{2}\right)$ showed similar HPLC chromatogram pattern, suggesting identical metabolic pathways toward several unknown nonpolar metabolites. These results are in line with the data reported by Fransson et al. in 2014. ${ }^{35}$

To further evaluate the stability of the two tracers, xenobiotic metabolism (phase I) was anticipated using freely available MetaPrint 2D tool, which predicts metabolism through data-mining and statistical analysis of known metabolic transformations reposted in the literature (Supporting Information Scheme 2). Based on this prediction, we postulated that the observed metabolites with shorter retention times on chromatograms (Figure 3) might be the hydroxylated $\left[{ }^{11} \mathrm{C}\right] \mathbf{1} /\left[{ }^{11} \mathrm{C}\right] \mathbf{2}$ on one of the aromatic rings. In order to test the hypothesis, additional LC-MS/MS experiments were performed as the methodology allows detection of the carrier amounts of ions involved in high molar activity PET tracers. A product ion scan analysis of nonpolar plasma fractions demonstrated a trace amount of 1 (Supporting Information Figure 5, blue) and two mass peaks of the hydroxylated parent ion (Supporting Information Figure 5, red), but unfortunately, it was not possible to identify if it was the phenylalanine or the carboxybenzyl hydroxylates. For the most abundant metabolite that increased rapidly overtime (Figure 3), we hypothesized that it was a glucuronidation of the compound.

Glucuronidation is known as the most important phase II metabolic pathway responsible for the clearance of many endogenous and exogenous compounds. ${ }^{37}$ Qualitative assessment using this MS/MS transition method of predicted metabolites with nonpolar plasma sample confirmed the glucorinated metabolite of $\left[{ }^{11} \mathrm{C}\right] \mathbf{1}$ (Supporting Information Figure 5, green). In addition, the nonpolar plasma samples from the in vivo stability study of $\left[{ }^{11} \mathrm{C}\right] 2$ were reanalyzed (Supporting Information Figure 5), all confirming postulated metabolites; a hydroxylation, oxidative deamination, or/and glucoronidation reaction. To clarify the position of the peaks, the glucoronated metabolite this time showed less retention on Kinetex Biphenyl column compared to the parent ion, due to glucuronide moiety possessing less pi-electrons. These results suggest that glucuronic acid is transferred to another nucleophilic atom in an acceptor parent molecule, where most likely $\mathrm{O}$-linked moiety (e.g., activation of the carboxylic group in phase I) would be the most preferred functional group for the reaction.

PET imaging with both compounds revealed rapid and homogeneous uptake throughout the brain and in the spinal cord followed by fast clearance (Figure 6A,D). Maximum accumulation of $\left[{ }^{11} \mathrm{C}\right] \mathbf{1}$ in brain was detected $3 \mathrm{~min}$ p.i. and after $10 \mathrm{~min}$ in spinal cord. Relatively fast clearance and liver and kidney uptake could be also attributed to $\left[{ }^{11} \mathrm{C}\right] \mathbf{1}$ potentially being bound to plasma proteins. ${ }^{11}$ Superior plasma stability of $\mathrm{D}$-analogue $\left[{ }^{11} \mathrm{C}\right] \mathbf{2}$ was reflected in PET imaging by higher accumulation and slower clearance pattern from the brain and spinal cord, which suggests that $\left[{ }^{11} \mathrm{C}\right] 2$ is a better imaging PET tracer than $\left[{ }^{11} \mathrm{C}\right] \mathbf{1}$.

Blocking experiments with natural heptapeptide $\mathrm{SP}_{1-7}$, injected i.p. $15 \mathrm{~min}$ prior to tracer $\left[{ }^{11} \mathrm{C}\right] \mathbf{1}$ administration, did not show difference in brain between baseline and blocking scan (Figure 6B). The poor BBB permeability, stability of peptides in vivo, and difference between the binding in brain and spinal cord ${ }^{12,13}\left(\mathrm{SP}_{1-7}\right.$ : rat spinal cord membrane, $1.6 \mathrm{nM}$, vs rat ventral tegmental area, $3.9 \mathrm{nM}$ ) are possible reasons. Furthermore, a publication by Skogh et al. ${ }^{7}$ published very shortly after we conducted PET scans revealed the $\mathrm{SP}_{1-7}$ in vitro half-life in mouse plasma of $4.4 \mathrm{~min}$, which further explains the lack of blocking in brain. Intriguingly, a minor blocking was observed in the spinal cord with decreased SUV values (from 0.95 to 0.87 , Figure $5 \mathrm{C}$, black vs red line. This observation can be supported by Skogh et al.'s publication ${ }^{7}$ where they confirmed antiallodynic effect of $\mathrm{SP}_{1-7}$ observed after i.p. administration. It should be mentioned that we have used the same dose and way of administration for our blocking studies as Skogh. Surprisingly, this centrally located target was confirmed by the fact that the homogenate of spinal cord was used for their in vitro binding studies, but $\mathrm{SP}_{1-7}$ failed to display any measurable permeability in the Caco-2 cell 
monolayer. ${ }^{7}$ Pretreatment with nonradioactive 1 , injected i.v. in the tail vein $20 \mathrm{~min}$ prior to $\left[{ }^{11} \mathrm{C}\right] \mathbf{1}$, affected no measurable change in whole brain radioactivity uptake. Considering low metabolic stability unveiled during this investigation, nonradioactive 1 was also injected only $3 \mathrm{~min}$ prior to tracer $\left[{ }^{11} \mathrm{C}\right]$ 1, where we observed in brain an increase of the SUV values up to 2.0. This might be explained by the fact that the pretreatment with nonlabeled compound, also subjected to rapid xenobiotic metabolism, preserves more of the intact $\left[{ }^{11} \mathrm{C}\right] \mathbf{1}$ in the blood for BBB and BSCB penetration. Further, self-blocking by pretreatment of 1 resulted in unaltered SUV values at $10 \mathrm{~min}$, while SUV values for injection $3 \mathrm{~min}$ prior TOI were slightly increased at $3 \mathrm{~min}$, compared to baseline SUV values (Figure 5C, blue line).

In summary, self-blocking studies showed no specific binding in whole brain and spinal cord of $\left[{ }^{11} \mathrm{C}\right] \mathbf{1}$ over the duration of the scan (Figure 6E,F). In comparison, selfblocking with nonradioactive 2 prior injection of $\left[{ }^{11} \mathrm{C}\right] \mathbf{2}$ resulted in increased SUV values for brain regions and almost unaffected SUV values for spinal cord (top part; Figure 6E,F). It can be concluded that peptides, in particular $\mathrm{SP}_{1-7}$, show significant sensitivity to peptidase degradation. Further, increased permeability of the $\mathrm{BSCB}$ compared to $\mathrm{BBB}^{38}$ might explain our blocking only in the spinal cord with $\mathrm{SP}_{1-7}$. Worth mentioning in this context is also that $\mathrm{BBB}$ and $\mathrm{BSCB}$ passage can be affected by the disease model, e.g., peripheral nerve injury, used for studying neuropathic pain, ${ }^{39}$ compared to the healthy animal rats.

Taken together, rapid brain and spinal cord uptake of $\left[{ }^{11} \mathrm{C}\right] \mathbf{1}$ and $\left[{ }^{11} \mathrm{C}\right] 2$ not only confirms sufficient $\mathrm{BBB}$ and $\mathrm{BSCB}$ exposure but also indicates that both $\mathrm{L}$ - and $\mathrm{D}$-tracers are not likely to be substrates for efflux transporters, as it has been indicated for other H-Phe-Phe- $\mathrm{NH}_{2}$ analogues by Fransson. ${ }^{16}$ These initial studies showed that both candidates have good tracer properties, such as excellent metabolic stability in the brain and spinal cord and favorable pharmacokinetics with a maximum brain and spinal cord concentration of approx. 3 and 10 min, respectively, after bolus injection in rats, all important considerations for imaging of CNS. Further validation of the tracer candidates in the disease model is necessary to overcome the poor understanding of $\mathrm{SP}_{1-7}$ binding site on a molecular level, which hampers employment of appropriate blocking compounds.

\section{CONCLUSION}

In summary, an efficient and high yielding radiochemistry was exploited to develop two $\mathrm{SP}_{1-7}{ }^{11} \mathrm{C}$-benzylacarbamates 1 and 2. In silico commercial model and CNS PET MPO algorithm were able to predict the brain- and spinal cord-permeable radiotracer(s). Preclinical evaluation characterizing the metabolic stability, biodistribution, and in vivo PET imaging profile confirmed that peptidomimetics $\mathbf{1}$ and $\mathbf{2}$ enter the rodent brain and spinal cord. Altogether, these encouraging data suggest a promising starting point for further tracer validation.

\section{ASSOCIATED CONTENT}

\section{S Supporting Information}

The Supporting Information is available free of charge on the ACS Publications website at DOI: 10.1021/acs.molpharmaceut.8b00518.

List of abbreviations; prediction model results; chemical synthesis-control reaction, radiochemistry optimization;
HPLC chromatograms; spinal cord metabolite analysis; LC-MS/MS spectra; metabolism prediction; program for automated synthesis; mass calibration curve data (PDF)

\section{AUTHOR INFORMATION}

\section{Corresponding Author}

*Address: Radionuclide Center, Department of Radiology and Nuclear Medicine, VU University Medical Center, De Boelelaan 1085c, 1081 HV Amsterdam, The Netherlands. Email: ad.windhorst@vumc.nl.

\section{ORCID $\odot$}

Aleksandra Pekošak: 0000-0003-1705-9626

\section{Author Contributions}

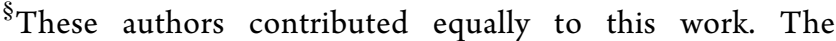
manuscript was written through contributions of all authors. All authors have given approval to the final version of the manuscript.

Notes

The authors declare no competing financial interest.

\section{ACKNOWLEDGMENTS}

The research leading to these results has been financially supported by the European Marie Curie Actions RADIOMI Initial Training Network (FP7-PEOPLE-2012-ITN) under project reference no. 316882. BV Cyclotron VU (Amsterdam) is acknowledged for providing $\left[{ }^{11} \mathrm{C}\right] \mathrm{CO}_{2}$.

\section{REFERENCES}

(1) Jonsson, A.; Fransson, R.; Haramaki, Y.; Skogh, A.; Brolin, E.; Watanabe, H.; Nordvall, G.; Hallberg, M.; Sandström, A.; Nyberg, F. Small Constrained SP1-7 Analogs Bind to a Unique Site and Promote Anti-Allodynic Effects Following Systemic Injection in Mice. Neuroscience 2015, 298, 112-119.

(2) Franzen, H. M.; Ragnarsson, U. Preperation and 11C-Labelling of a Substance P Analogue Containing D-Tryptophan in Positions 7 and 9. J. Chem. Soc., Perkin Trans. 1 1988, 1, 497-502.

(3) Wolfensberger, S. P. A.; van Berckel, B. N. M.; Airaksinen, A. J.; Maruyama, K.; Lubberink, M.; Boellaard, R.; Carey, W. D. H.; Reddingius, W.; Veltman, D. J.; Windhorst, A. D.; et al. First Evaluation of [11C]R116301 as an in Vivo Tracer of NK1 Receptors in Man. Mol. Imaging Biol. 2009, 11 (4), 241-245.

(4) Hargreaves, R. Imaging Substance P Receptors (NK1) in the Living Human Brain Using Positron Emission Tomography. Psychiatry Interpers. Biol. Process. 2002, 63, 18-24.

(5) Fransson, R.; Botros, M.; Sköld, C.; Nyberg, F.; Lindeberg, G.; Hallberg, M.; Sandström, A. Discovery of Dipeptides with High Affinity to the Specific Binding Site for Substance P1-7. J. Med. Chem. 2010, 53 (6), 2383-2389.

(6) Kastin, A. J. Handbook of Biologically Active Peptides; Elsevier, 2013.

(7) Skogh, A.; Lesniak, A.; Gaugaz, F. Z.; Svensson, R.; Lindeberg, G.; Fransson, R.; Nyberg, F.; Hallberg, M.; Sandström, A. Importance of N- and C-Terminal Residues of Substance P 1-7 for Alleviating Allodynia in Mice after Peripheral Administration. Eur. J. Pharm. Sci. 2017, 106, 345-351.

(8) Zhou, Q.; Liu, Z.; Ray, A.; Huang, W.; Karlsson, K.; Nyberg, F. Alteration in the Brain Content of Substance P (1-7) during Withdrawal in Morphine-Dependent Rats. Neuropharmacology 1998, 37 (12), 1545-1552.

(9) Botros, M.; Hallberg, M.; Johansson, T.; Zhou, Q.; Lindeberg, G.; Frändberg, P. A.; Tömböly, C.; Tóth, G.; Le Grevès, P.; Nyberg, F. Endomorphin-1 and Endomorphin-2 Differentially Interact with Specific Binding Sites for Substance P (SP) Aminoterminal SP1-7 in the Rat Spinal Cord. Peptides 2006, 27 (4), 753-759. 
(10) Botros, M.; Johansson, T.; Zhou, Q.; Lindeberg, G.; Tömböly, C.; Tóth, G.; Le Grevès, P.; Nyberg, F.; Hallberg, M. Endomorphins Interact with the Substance P (SP) Aminoterminal SP1-7binding in the Ventral Tegmental Area of the Rat Brain. Peptides 2008, 29 (10), $1820-1824$.

(11) Fransson, R.; Nordvall, G.; Bylund, J.; Carlsson-Jonsson, A.; Kratz, J. M.; Svensson, R.; Artursson, P.; Hallberg, M.; Sandstro, A. Exploration and Pharmacokinetic Profiling of Phenylalanine Based Carbamates as Novel Substance P1-7 Analogues. ACS Med. Chem. Lett. 2014, 5 (1), 1272-1277.

(12) Fransson, R.; Botros, M.; Nyberg, F.; Lindeberg, G.; Sandström, A.; Hallberg, M. Small Peptides Mimicking Substance P (1-7) and Encompassing a C-Terminal Amide Functionality. Neuropeptides 2008, 42 (1), 31-37.

(13) Zhou, Q.; Carlsson, A.; Botros, M.; Fransson, R.; Sandstrom, A.; Gordh, T.; Hallberg, M.; Nyberg, F. The C-Terminal Amidated Analogue of the Substance P (SP) Fragment SP1-7 Attenuates the Expression of Naloxone-Precipitated Withdrawal in Morphine Dependent Rats. Peptides 2009, 30 (12), 2418-2422.

(14) Botros, M.; Hallberg, M.; Johansson, T.; Zhou, Q.; Lindeberg, G.; Fra, P. Endomorphin-1 and Endomorphin-2 Differentially Interact with Specific Binding Sites for Substance P (SP) Aminoterminal SP 1-7 in the Rat Spinal Cord. Peptides 2006, 27, 753-759.

(15) Igwe, O. J.; Kim, D. C.; Seybold, V. S.; Larson, a a. Specific Binding of Substance P Aminoterminal Heptapeptide $[\mathrm{SP}(1-7)]$ to Mouse Brain and Spinal Cord Membranes. J. Neurosci. 1990, 10 (11), $3653-3663$.

(16) Fransson, R.; Sköld, C.; Kratz, J. M.; Svensson, R.; Artursson, P.; Nyberg, F.; Hallberg, M.; Sandström, A. Constrained H-Phe-PheNH2 Analogues with High Affinity to the Substance P 1-7 Binding Site and with Improved Metabolic Stability and Cell Permeability. J. Med. Chem. 2013, 56 (12), 4953-4965.

(17) R, B.; Baron, R. Mechanisms of Disease: Neuropathic Pain - A Clinical Perspective. Nat. Clin. Pract. Neurol. 2006, 2 (2), 95-106.

(18) Colloca, L.; Ludman, T.; Bouhassira, D.; Baron, R.; Dickenson, A. H.; Yarnitsky, D.; Freeman, R.; Truini, A.; Attal, N.; Finnerup, N. B.; et al. Neuropathic Pain. Nat. Rev. Dis. Prim. 2017, 3, 17002.

(19) Gunn, R. N.; Rabiner, E. A. Imaging in Central Nervous System Drug Discovery. Semin. Nucl. Med. 2017, 47 (1), 89-98.

(20) Lever, S. Z.; Fan, K. H.; Lever, J. R. Tactics for Preclinical Validation of Receptor-Binding Radiotracers. Nucl. Med. Biol. 2017, 44, 4-30.

(21) Miller, P. W.; Long, N. J.; Vilar, R.; Gee, A. D. Synthesis of 11 $\mathrm{C}, 18 \mathrm{~F}, 15 \mathrm{O}$, and $13 \mathrm{~N}$ Radiolabels for Positron Emission Tomography. Angew. Chem., Int. Ed. 2008, 47 (47), 8998-9033.

(22) Dahl, K.; Halldin, C.; Schou, M. New Methodologies for the Preparation of Carbon-11 Labeled Radiopharmaceuticals. Clin. Transl. Imaging 2017, 5 (3), 275-289.

(23) Antoni, G. Development of Carbon-11 Labelled PET TracersRadiochemical and Technological Challenges in a Historic Perspective. J. Labelled Compd. Radiopharm. 2015, 45, 65-72.

(24) Wadsak, W.; Mitterhauser, M. Basics and Principles of Radiopharmaceuticals for PET/CT. Eur. J. Radiol. 2010, 73 (3), 461-469.

(25) Vallabhajosula, S.; Solnes, L.; Vallabhajosula, B. A Broad Overview of Positron Emission Tomography Radiopharmaceuticals and Clinical Applications: What Is New? Semin. Nucl. Med. 2011, 41 (4), 246-264.

(26) Rotstein, B. H.; Liang, S. H.; Placzek, M. S.; Hooker, J. M.; Wilson, A. A.; Vasdev, N. 11C =O Bonds Made Easily for Positron Emission Tomography Radiopharmaceuticals. Chem. Soc. Rev. 2016, 45 (17), 4708-4726.

(27) Pekošak, A.; Rotstein, B. H.; Collier, T. L.; Windhorst, A. D.; Vasdev, N.; Poot, A. J. Stereoselective ${ }^{11}$ C-Labeling of a "Native" Tetrapeptide Using Asymmetric Phase-Transfer Catalyzed Alkylation Reactions. Eur. J. Org. Chem. 2017, 2017 (5), 1019-1024.

(28) Miller, P. W.; Long, N. J.; Vilar, R.; Gee, A. D. Synthesis of $11 \mathrm{C}, 18 \mathrm{~F}, 15 \mathrm{O}$, and $13 \mathrm{~N}$ Radiolabels for Positron Emission Tomography. Angew. Chem., Int. Ed. 2008, 47 (47), 8998-9033.
(29) Hooker, J. M.; Reibel, A. T.; Hill, S. M.; Schueller, M. J.; Fowler, J. S. One-Pot, Direct Incorporation of [11C]CO2 into Carbamates. Angew. Chem., Int. Ed. 2009, 48 (19), 3482-3485.

(30) Wilson, A. a; Garcia, A.; Houle, S.; Vasdev, N. Direct Fixation of [(11)C]-CO(2) by Amines: Formation of [(11)C-Carbonyl]Methylcarbamates. Org. Biomol. Chem. 2010, 8 (2), 428-432.

(31) Zhang, L.; Villalobos, A.; Beck, E. M.; Bocan, T.; Chappie, T. A.; Chen, L.; Grimwood, S.; Heck, S. D.; Helal, C. J.; Hou, X.; et al. Design and Selection Parameters to Accelerate the Discovery of Novel Central Nervous System Positron Emission Tomography (PET) Ligands and Their Application in the Development of a Novel Phosphodiesterase 2A PET Ligand. J. Med. Chem. 2013, 56, 45684579.

(32) Zhang, L.; Villalobos, A. Strategies to Facilitate the Discovery of Novel CNS PET Ligands. EJNMMI Radiopharm. Chem. 2017, 1, 112.

(33) Wager, T. T.; Hou, X.; Verhoest, P. R.; Villalobos, A. ACS Chem. Neurosci. 2010, 1, 435-449.

(34) Windhorst, A. D.; ter Linden, T.; de Nooij, A.; Keus, J. F.; Buijs, F. L.; Schollema, P. E.; van Rooij, L. F.; Herscheid, J. D. M. A Complete, Multipurpose, Low Cost, Fully Automated and GMP Compliant Radiosynthesis System. J. Labelled Compd. Radiopharm. 2001, 44 (S1), S1052-S1054.

(35) Fransson, R.; Nordvall, G.; Bylund, J.; Carlsson-Jonsson, A.; Kratz, J. M.; Svensson, R.; Artursson, P.; Hallberg, M.; Sandstro, A. Exploration and Pharmacokinetic Pro Fi Ling of Phenylalanine Based Carbamates as Novel Substance P $1-7$ Analogues. ACS Med. Chem. Lett. 2014, 5, 1272-1277.

(36) Murata, T.; Umeda, M.; Yoshikawa, S.; Urbahns, K.; Gupta, J.; Osamu, S. Phenyl or Heteroaryl Amino Alkane Derivatives As IP Receptor Antagonist. WO2004043926 (A1), 2004.

(37) Ge, S.; Tu, Y.; Hu, M. Challenges and Opportunities with Predicting In Vivo Phase II Metabolism via Glucuronidation From In Vitro Data. Curr. Pharmacol. Reports 2016, 2 (6), 326-338.

(38) Bartanusz, V.; Jezova, D.; Alajajian, B.; Digicaylioglu, M. The Blood-Spinal Cord Barrier: Morphology and Clinical Implications. Ann. Neurol. 2011, 70 (2), 194-206.

(39) Jaggi, A. S.; Jain, V.; Singh, N. Animal Models of Neuropathic Pain. Fundam. Clin. Pharmacol. 2011, 25 (1), 1-28. 